\title{
EL USO DE TÉCNICAS GEOFÍSICAS PARA DETERMINAR SISTEMAS CONSTRUCTIVOS Y MATERIALES PRESENTES EN LOS TÚMULOS DEL PERÍODO FORMATIVO EN EL VALLE DE AZAPA, ARICA, CHILE
}

\author{
USING OF GEOPHYSICAL TECHNIQUES TO DETERMINE BUILDING \\ SYSTEMS AND MATERIALS PRESENT IN THE TUMULI OF THE FORMATIVE \\ PERIOD IN THE AZAPA VALLEY, ARICA, CHILE
}

\author{
Luis Barba ${ }^{1}$ Iván Muñoz ${ }^{2}$, Agustín Ortiz ${ }^{1}$ y Jorge Blancas ${ }^{1}$
}

\begin{abstract}
Como resultado de un proyecto conjunto entre la Universidad Nacional Autónoma de México y la Universidad de Tarapacá, Chile, se realiza por primera vez en el valle de Azapa, norte de Chile, un estudio geofísico que incluye técnicas de gradiente magnético y georradar. Este valle ha sido el origen de asentamientos humanos tempranos vinculados con la tradición Chinchorro. Posteriormente en el último milenio antes de Cristo, junto con el desarrollo inicial de la agricultura, las poblaciones erigieron monumentos de alta visibilidad, en ellos depositaron cuerpos y osamentas humanas, las que periódicamente eran removidas con fines ceremoniales. Excavaciones arqueológicas previas en el sitio Az- 80 han revelado que la mayoría de los montículos fueron construidos con capas alternas de vegetación y de sedimentos. Es destacable la conservación de los materiales orgánicos en este ambiente del desierto de Atacama, uno de los más áridos del mundo. Todo lo anterior ha preservado la forma y tamaño de los montículos, lo que permite el uso de técnicas geofísicas. Entre ellas se seleccionó el estudio magnético con el gradiómetro Geoscan FM36 y el estudio con georradar SIR 3000 de GSSI con una antena de $400 \mathrm{MHz}$.

Los resultados de esta primera aproximación revelaron que el gradiente magnético detectó el uso de piedras ligeramente magnéticas colocadas en lugares específicos durante la construcción del túmulo, pero lo más importante es que las reflexiones del radar revelaron la presencia de etapas constructivas anteriores en el interior de los túmulos, y en algunos casos lo que pudieran ser enterramientos y pequeñas estructuras funerarias.
\end{abstract}

Palabras claves: túmulos, montículos, georradar, gradiómetro, desierto de Atacama.

As a result of a joint research project between the Universidad Nacional Autónoma de México and the Universidad de Tarapacá, Norte de Chile, a geophysical study, which included magnetic gradient and georadar techniques, was carried out for the first time in the Azapa Valley. This valley has been the origin of early human settlements linked to the Chinchorro tradition. Subsequently, in the last millennium BC, along with the initial development of agriculture, these populations built highly visible monuments, in which bodies and human remains were deposited, which were periodically removed for ceremonial purposes.

Some previous archaeological excavations in the Az-80 archaeological site have revealed that most of the mounds were built using alternated layers of vegetation and sediments. The preservation of the organic materials in this environment of the Atacama Desert, one of the driest in the world, is remarkable. This has helped preserve the shape and size of the mounds and has allowed the use of geophysical techniques. From these techniques, we decided to use the gradiometer Geoscan FM36 and the georadar SIR 3000 from GSSI with $400 \mathrm{MHz}$ antenna.

Results of this first approach revealed that magnetic gradient detected the use of slightly magnetic stones in specific places during the building of the mounds. Most importantly, however, is that the radar reflections revealed previous building stages inside the mounds and in some cases what might be some burials and small funerary structures.

Key words: Tumuli, mounds, georadar, gradiometer, Atacama Desert.

\footnotetext{
1 Laboratorio de Prospección Arqueológica, Instituto de Investigaciones Antropológicas, Universidad Nacional Autónoma de México, Ciudad Universitaria, México, D.F. 04510, México. barba@unam.mx; ortizbutron@ gmail.com; jorgeblancasvaz@gmail.com

2 Departamento de Antropología, Universidad de Tarapacá, Arica, Chile. imunoz@uta.cl
} 
La construcción de los túmulos constituye el primer indicio de arquitectura prehispánica monumental, que se remonta hacia los 3.000 años a.p. en los valles costeros del desierto de Atacama. Constituirían, después de la tradición Chinchorro, las evidencias más conspicuas para entender el proceso de complejidad social incipiente, y los cambios operados en los grupos de pescadores y recolectores de la costa del norte de Chile y extremo sur de Perú. El registro arqueológico señala que las poblaciones constructoras de túmulos están vinculadas estrechamente a prácticas agrícolas tempranas y a los cambios socioeconómicos que derivaron en el establecimiento de un régimen de vida sedentario. Constituyen las muestras visibles de un patrón de asentamiento cuyos constructores se hallaban en proceso de demarcar territorios, posiblemente en función de la disponibilidad de los recursos que ofrecía el medio, y que demandaba una legitimidad acerca de dichos espacios aduciendo un uso ancestral, lo que se hizo visible con la construcción de túmulos.

La presente investigación aborda la búsqueda de metodologías que nos permitan obtener mayor información arqueológica empleando técnicas geofísicas como el georradar y el gradiómetro sin alterar estos monumentos construidos por capas de tierra y fibra vegetal en un ambiente desértico. Experiencias anteriores en estos ambientes con muy baja humedad han mostrado que el funcionamiento del georradar es óptimo. En Egipto utilizaron el GPR (Yoshimura et al. 1987) para estudiar la estructura interna de la gran pirámide, la constitución de la esfinge y para tratar de determinar el momento en que fue usada. Más recientemente, las investigaciones en la necrópolis de Saqqara, la plataforma de Gizah y Quesna confirmaron que el georradar es efectivo para el estudio de este tipo de contextos (Abbas et al. 2006). En otra experiencia en ambiente desértico en la península de Baja California, México, se logró una penetración cercana a $10 \mathrm{~m}$ con una antena de $200 \mathrm{MHz}$ para localizar asentamientos antiguos de cazadores recolectores (Barba et al. 2008). En ambientes andinos se tiene el antecedente del trabajo de Bonomo et al. (2013). De esta manera, esperamos que sin excavar se podrá obtener información complementaria a la que tradicionalmente se ha obtenido mediante la excavación en túmulos en el valle de Azapa.

De lo anteriormente planteado, nuestros objetivos apuntan a identificar y analizar comportamientos humanos, procesos constructivos y captación de recursos dentro de la formación del túmulo. Para tal efecto se seleccionaron dos unidades de túmulos, Az-24 y Az-80. Su selección obedeció a que previamente habían sido excavados en un porcentaje menor, sin embargo presentaban perfiles expuestos, lo que hacía visible una parte de los sistemas constructivos y algunos comportamientos humanos de carácter ceremonial (Figura 1).

\section{Antecedentes Arqueológicos de los Túmulos del Valle de Azapa}

Los túmulos constituyen estructuras sólidas ligadas visualmente al entorno, se presentan como montículos emplazados en los faldeos de cerros y terrazas, ubicados en sectores estratégicos del valle, con la presencia de agua, plantas y amplias terrazas, lo que les permitió evitar los ambientes malsanos. Desde el punto de vista de su estructura, están conformados por una serie de capas con fibra vegetal superpuestas con capas inertes de áridos o tierra. Las capas de fibra vegetal en ocasiones se presentan cubriendo entierros y osamentas humanas, en otros casos cubren ofrendas depositadas al túmulo, estas ofrendas corresponden a distintos períodos precolombinos, llegando incluso hasta el período colonial (Muñoz 2004).

Dataciones de carbono 14 señalan que los túmulos comenzaron a construirse a partir del último milenio antes de Cristo. Esta tradición de construir estructuras elevadas si bien es propia del proceso formativo, el uso de esteras y pequeñas camadas de fibra vegetal es conocido en los entierros de la costa de Arica desde el período Arcaico Temprano (7.000 a.C.) (Santoro et al. 2012; Standen y Santoro 2004; Umire 2013), por lo tanto la construcción de estos monumentos obedece a una tradición local cuyos actores habrían sido los pescadores de la costa que ocupan los valles, en terrazas cercanas a los recursos de vertientes. En el caso de Azapa, el conocimiento del valle por parte de los pescadores en la búsqueda de recursos complementarios era conocido desde el período Arcaico, por lo tanto había una relación directa con este valle, en el sentido de explotar los recursos naturales que ofrecía.

Desde el punto de vista constructivo, el mayor desarrollo de los túmulos se habría alcanzado entre el 500 al 200 a.C. y estaría relacionado con las primeras aldeas de agricultores conocidas para estos valles. Construyeron montículos en distintos 


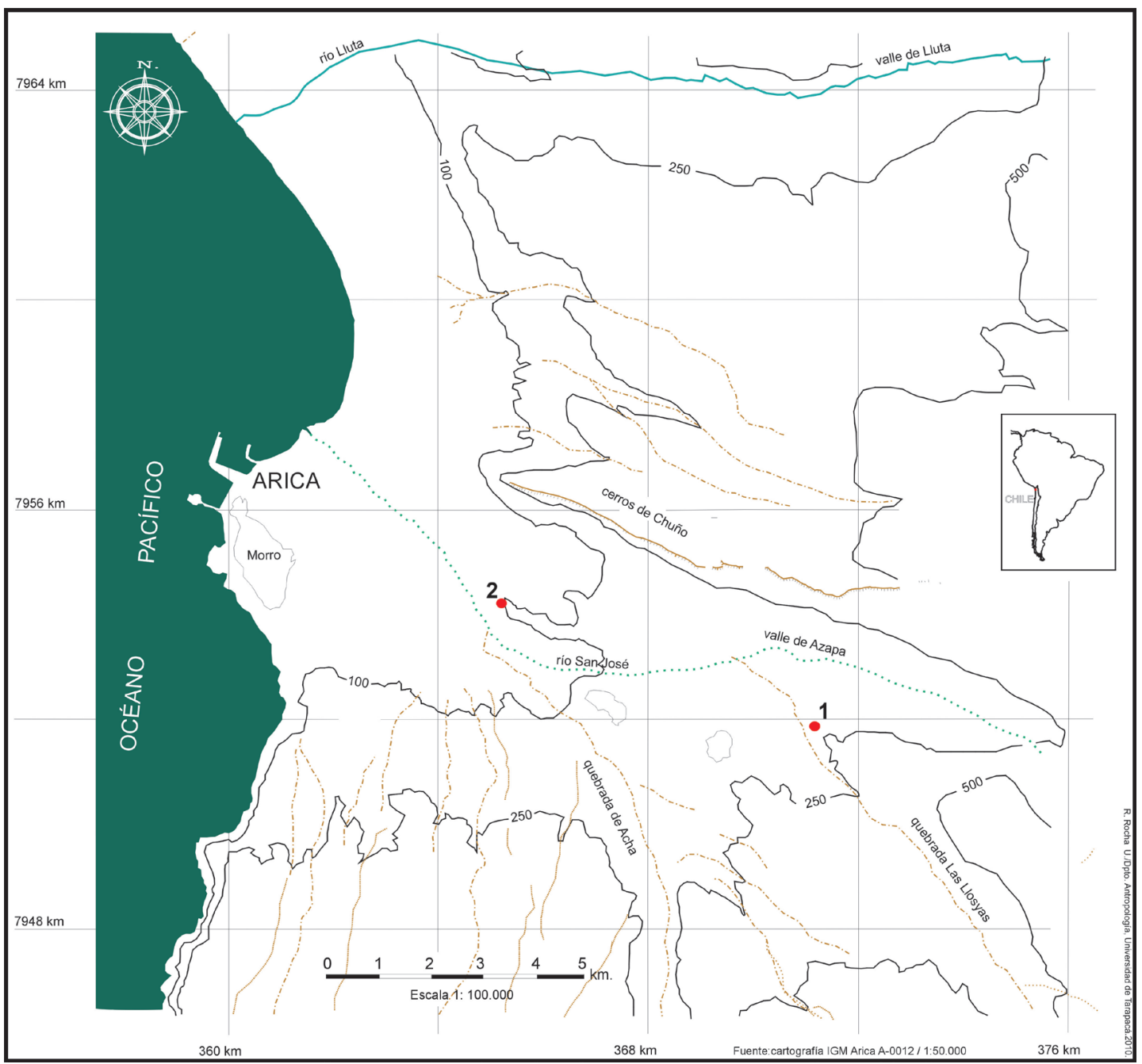

Figura 1. Ubicación de los sitios estudiados Az-80 (1) y Az-24 (2).

Location of the sites studied: AZ-80 (1) and AZ-24 (2).

sectores sincrónicamente y en relación directa con los ecosistemas de humedales y vertientes, primeras tecnologías agrícolas como acequias y canales, constituyendo todo este paisaje social, lo que le dio identidad a los pescadores ariqueños en tránsito hacia la agricultura (Muñoz 2010).

En general las estructuras monticulares responden de muy buena manera a las condiciones climáticas. Contra el viento responden de manera aerodinámica debido a la suave sinuosidad de sus curvas permitiendo tener una muy baja erosión por viento (Muñoz y Gutiérrez 2011). Contra la humedad responden mediante su composición de capas alternadas entre vegetales e inertes, que impermeabilizan los túmulos creando una protección adecuada para los vestigios y enseres que albergaban. Esto se ve ejemplificado cuando se observa que solamente las capas más superficiales presentan un ligero deterioro debido a la humedad y la erosión.

En cuanto al entorno como condicionante de asentamiento con túmulos, este se encuentra muy marcado tanto por las condiciones climatológicas propias del valle como por la capacidad de obtener recursos para sus construcciones. Por lo tanto, hay una estrecha relación del asentamiento humano reflejado en los túmulos con las fuentes de abastecimiento, como los recursos hídricos (vertientes), materias primas (canteras) y recursos de subsistencia (humedales), además de lugares o hitos geográficos vinculados con el mundo ceremonial. 
De esta manera los túmulos construidos a lo largo del valle de Azapa pudieron haber constituido nodos logísticos estratégicos, ya que se encuentran en un lugar de circulación que une el valle con el mar, y liga el acceso de circulación hacia el interior del valle y mediante la quebrada del Diablo que la conecta con el valle de Lluta.

En cuanto a su funcionalidad, además de ser espacios donde se depositaron restos humanos, fueron objeto de ceremonias en períodos posteriores que perduraron hasta la llegada del europeo. Según Muñoz (2012), en estos montículos habría una estrecha relación con un ceremonialismo que monumentalizó el espacio de los muertos. Por su parte Romero et al. (2004) señalan que los túmulos pudieron haber sido construcciones ceremoniales relacionadas a componentes ideológicos de modificación del paisaje; lo que reflejaría un nuevo orden social de las tempranas sociedades agrícolas.

En cuanto al porqué se construyeron estas obras monumentales, diversas son las hipótesis que se pueden conjugar. Desde el punto de vista del paisaje, presentan una estrecha similitud con los cerros, por lo que se podría hablar de imitación. Señalemos que los cerros o montañas representan ciertos puntos liminares, por ejemplo, el punto de unión entre el mundo terrenal y el cielo, constituyen referentes fijos, marcadores del paisaje que lo ordenan (espacio), están dotados de poderes especiales que implican el nexo con lo sobrenatural. En el caso del mundo andino los cerros están asociados a la fertilidad, en otros casos son venerados porque figuran en el mito de origen. Los cerros son los apus los que están cargados de significados, influencias buenas y malas según la ocasión. Además se relacionan directamente con los ancestros porque allí viven las almas tutelares.

\section{Características de los Túmulos Estudiados en el Valle de Azapa}

Los antecedentes respecto de los patrones constructivos, áreas y materialidad utilizada en la construcción de los túmulos señalan en relación con la selectividad del área de construcción que estos ocuparon las cotas inferiores de laderas y planos de terraza. Las áreas donde se construyeron los túmulos responden a un posicionamiento estratégico con relación al aprovisionamiento de materias primas, visualización a distancia en relación con otras áreas de poblamiento, control, movilidad y confluencia de espacios rituales, etc.

Varias de las terrazas donde fueron construidos los túmulos presentan desprendimientos de materiales producto de una actividad geomorfológica con desplazamientos de terreno hacia la caja del valle, exponiendo material rocoso y dejando planos estrechos que fueron aprovechados para construir un complejo de túmulos con tres a cinco ejemplares. Por su composición natural insertos en laderas y lomas naturales, estos túmulos aparte de mimetizarse se integran a la morfología geográfica del valle, lo que hace que aún a ojo de experto se dificulte su reconocimiento.

Por el hecho de que están cercanos a fallas geológicas, las rocas utilizadas son de distintos tipos, en cuanto a formas y tamaños, y se incorporan a la estratigrafía constructiva de las capas áridas. Los bloques de mayor volumen fueron empleados para la talla de petroglifos y para insertarlos en la estratigrafía de los túmulos.

Los túmulos que hemos llamado de construcción en el plano de terraza, se caracterizan por presentar un crecimiento orgánico que trata de imitar una serranía o conjunto de lomas naturales como es el caso de Az-17 y Az-80. Presentan distintas alturas y extensión alcanzando un máximo de $6 \mathrm{~m}$ de altura y alrededor de $30 \mathrm{~m}$ de diámetro. El análisis de cada complejo de túmulos nos ha permitido ver su conexión por medio de vías de desplazamiento entre ellos. Las conexiones se producen a nivel de la base, y a medianas alturas, de tal modo que generan depresiones suaves y sinuosas que permiten el paso entre ellos.

Respecto del uso del material árido, en los túmulos de Az-67 pudimos observar que están sustentados por tierra, arena y cascajos, las formas de estos túmulos son de cimas estrechas y redondeadas, de faldeos curvos y extensos. En relación con el uso de la fibra vegetal observamos por ejemplo que, en el caso del túmulo 1, estrato 15 (el más antiguo), se presenta un caso particular de preparación de una camada; está conformada por ramas, raíces y hojas a diferencia de otras camadas más superficiales que están compuestas por pastos y hojas más finas, lo que demostraría una selectividad cada vez más depurada de estas camadas de fibra vegetal en la medida que se fue construyendo el túmulo. En este mismo túmulo observamos que las áreas de captación del material árido estaban a su alrededor y son depresiones no 
muy profundas que es posible observar hasta hoy (Muñoz y Gutiérrez 2011).

\section{Las Técnicas Geofísicas}

\section{Gradiente magnético}

Los magnetómetros y los gradiómetros son particularmente eficientes para detectar zonas quemadas, como hornos y fogones; asimismo pueden detectar muros, fosas y trincheras. Su principal ventaja es que la técnica cubre grandes extensiones de terreno en corto tiempo, lo que permite obtener el mapa magnético del terreno con un tiempo-costo muy razonable (Gaffney y Gater 2003).

La prospección magnética se basa, entre otras cosas, en el contraste de propiedades físicas que son consecuencia del contenido de pequeñas cantidades de minerales magnéticos como magnetita, ilmenita, óxidos de hierro, cobalto y níquel en los materiales que forman el suelo. Dependiendo del grado de magnetización y la abundancia de estos minerales, la superficie del terreno exhibirá una magnetización débil o sólida (Blancas 2012).

La magnetización de los materiales es ocasionada por la inducción del campo magnético terrestre y por la acción termorremanente. La intensidad de la magnetización inducida depende principalmente de la susceptibilidad magnética $\left(\chi_{\mathrm{M}}\right)$ y de las características del campo magnético terrestre. En cambio, la acción remanente depende de la historia geológica o arqueológica de los materiales y de cambios súbitos de temperatura; su valor es independiente del valor actual del campo magnético terrestre. Casi siempre la magnetización por inducción $\left(\mathrm{M}_{\mathrm{i}}\right)$ es mayor que la remanente $\left(\mathrm{M}_{\mathrm{r}}\right)$, pero hay situaciones, comúnmente encontradas en la prospección arqueológica, en donde la remanente resulta mucho mayor, como es el caso de los hornos y las superficies sometidas a calentamiento.

La magnetización total $\left(\mathrm{M}_{\mathrm{T}}\right)$ del cuerpo se expresa como:

$$
\mathrm{M}_{\mathrm{T}}=\mathrm{M}_{\mathrm{r}}+\mathrm{M}_{\mathrm{i}}
$$

Para la medición del gradiente magnético vertical se utiliza como instrumento el gradiómetro, su funcionamiento es equivalente a un magnetómetro diferencial, en donde el espaciamiento entre los sensores es fijo y pequeño respecto de las fuentes generadoras de campos magnéticos (por ejemplo, estructuras de piedra). La diferencia entre los campos medidos dividida por la distancia que separa los sensores es el gradiente asignado al punto medio del espaciamiento entre ellos (Figura 2).

Para el valle de Azapa se adquirieron lecturas en modo de gradiente magnético vertical, con el gradiómetro Geoscan FM36 con $0.1 \mathrm{nT}$ (nanoteslas) de sensibilidad. Los datos fueron tratados con diferentes técnicas de proceso con el software Geoplot (Geoscan Research 2005) para corregir errores en la adquisición de datos, atenuar parte del ruido magnético moderno e interpolar los datos para una buena representación. Algunos de los procesos empleados fueron la interpolación, despike (elimina lecturas aleatorias espurias fuera de rango causado por basura metálica en la superficie), destagger (corrige el desplazamiento de las anomalías causadas por la adquisición en zigzag), low pass filter (suaviza los datos al remover el ruido de alta frecuencia producido por pequeños elementos magnéticos superficiales) y zero-mean grid (establece un umbral promedio para las retículas levantadas en distintos horarios para crear un mapa promedio representativo del sitio). Una vez procesados, los datos fueron representados con el programa Transform (Transform 1990-1996) en mapas de pseudocolor.

Esta técnica remueve de forma automática el campo magnético regional $\mathrm{y}$, de esta forma, define mejor las anomalías superficiales que para estudios arqueológicos son de gran importancia para la interpretación. También remueve los efectos producidos por las variaciones diurnas, las tormentas magnéticas y las interferencias presentes en condiciones urbanas.

\section{Radar de penetración terrestre o georradar}

El georradar o radar de penetración terrestre (ground penetrating radar, gpr) es una técnica geofísica activa que utiliza ondas electromagnéticas

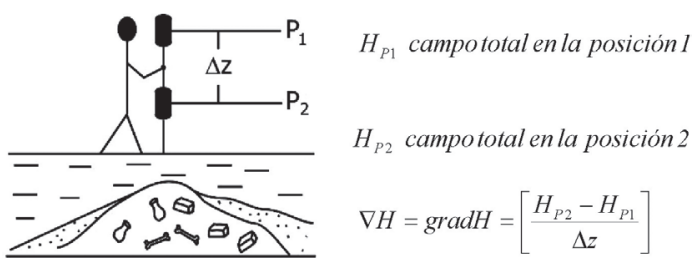

Figura 2. Estudio de gradiente magnético sobre la superficie del terreno.

Magnetic gradient survey on mounds surface. 
de radiofrecuencia del orden de 10 a $2.500 \mathrm{MHz}$, que son enviadas al interior del subsuelo, para registrar las ondas reflejadas y construir una imagen bidimensional en tiempo o profundidad de los objetos enterrados.

Los fundamentos del georradar son simples, la antena transmite ondas de radiofrecuencia al subsuelo, cuando llegan a la interfase entre dos materiales con propiedades electromagnéticas diferentes $(\sigma$ conductividad, $\varepsilon$ constante dieléctrica, $v$ velocidad de propagación, $\mu$ permeabilidad magnética), parte de ellas se reflejan, mientras que otras son transmitidas al interior del subsuelo y se atenúan en función de la distancia. El sistema medirá el tiempo transcurrido entre las ondas transmitidas y las reflejadas, esta sucesión de eventos se repite en intervalos de tiempo muy cortos, del orden de nanosegundos, mientras la antena está en movimiento, entonces las ondas reflejadas se representarán como trazas consecutivas, correspondientes a las distintas posiciones de la antena sobre la superficie del terreno, formando un perfil continuo llamado radargrama (Blancas 2000) (Figura 3).

La capacidad de esta técnica para "ver" lo que hay debajo de la superficie a distintas profundidades la convierte en una herramienta de gran interés para la investigación arqueológica, ya que se pueden planear estrategias de excavación a partir de la información recuperada. Como consecuencia de esto, el georradar ha sido una de las técnicas con
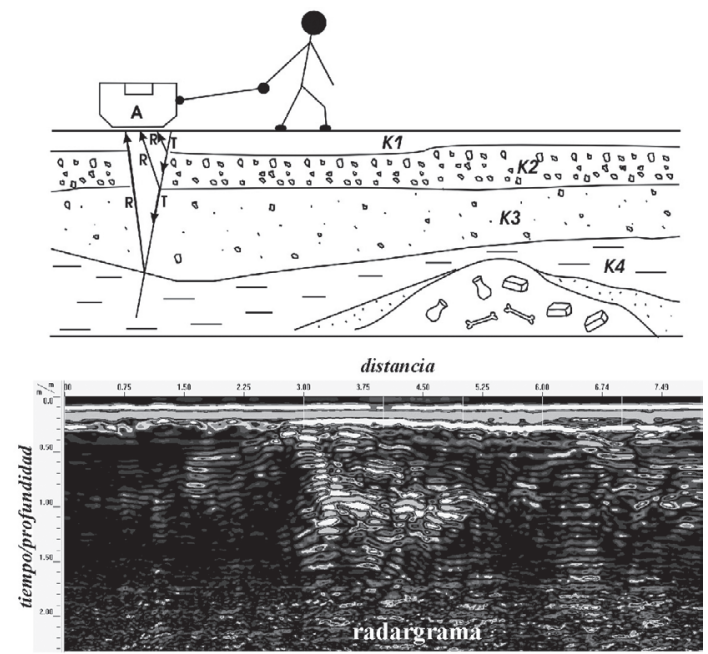

Figura 3. Adquisición de datos de radar con arreglo de reflexión en modo continuo y radargrama obtenido.

Georadar survey with continued reflection mode and the collected radargram. mayor crecimiento en la investigación arqueológica durante los últimos 25 años. La ventaja principal del georradar es que ofrece secciones transversales del subsuelo, que adquiridas sistemáticamente en una retícula, aportará imágenes tridimensionales del sitio estudiado. El resultado será una serie de planos horizontales a distintas profundidades llamados cortes de profundidad, similares a los obtenidos en una tomografía médica (Blancas 2012).

En suelos arcilloarenosos esta técnica es particularmente buena para detectar construcciones de roca debido al contraste en propiedades electromagnéticas (Annan y Cosway 1992). Generalmente el georradar es eficiente cuando hay buen contraste dieléctrico entre el objeto de interés y su entorno. Sin embargo, varios factores deben ser considerados para tener un estudio exitoso: la profundidad del objeto, las condiciones de la superficie del terreno, la composición y las propiedades físicas de los materiales enterrados y el medio en el que se encuentran.

La adquisición de los datos fue realizada con un equipo SIR System 3000 de GSSI y una antena monoestática de $400 \mathrm{MHz}$ en modo continuo, para explorar el subsuelo hasta una profundidad aproximada de $3 \mathrm{~m}$. Los perfiles de georradar se recolectaron con una ventana de tiempo de $60 \mathrm{~ns}$, 32 trazas por segundo y 512 muestras por traza. Los datos se procesaron con el programa Radan $6.6 \mathrm{de}$ GSSI para remover ruido (filtros en frecuencia), mejorar la resolución horizontal y vertical (filtros espaciales), y estimar la profundidad de penetración. Algunos de los procesos empleados fueron: filtrado paso-banda con frecuencias de corte de 100-800 $\mathrm{MHz}$, filtro espacial running average (promedios corridos) de siete trazas, normalización de distancias, ajuste de ganancias y apilamiento (stack) de dos para mejorar la relación señal-ruido.

\section{Sitio Az-24}

Ubicación geográfica y descripción del túmulo. Esta reserva arqueológica constituye una unidad cohesionada conformada por cuatro túmulos a simple vista, en sus cotas más bajas se asocia a un cementerio correspondiente al período Medio. En su flanco norte se ubica una colina conocida como cerro San Miguel, cuya extensión alcanza los 1.400 $\mathrm{m}$ de noroeste a sureste. Posee una altura máxima sobre plano de $16 \mathrm{~m}$, declinando por el flanco noroeste en $5 \mathrm{~m}$. 
Desde este sitio se tiene dominio visual del flanco sur del valle de Azapa, entre ella, la formación natural de cerro Sombrero, hacia el sureste se observa la confluencia de la quebrada de Acha con el valle de Azapa. Finalmente hacia el suroeste se observa el paso que une el valle de Azapa con el sector costero de Quiani y el promontorio rocoso del morro de Arica.

Estado de conservación del sitio. Alrededor de este complejo de túmulos se encuentran dos asentamientos humanos actuales con constante tránsito sobre la reserva arqueológica que generan erosión y, en consecuencia, exponen al medio los niveles superficiales de la estratigrafía arqueológica vegetal. La instalación de servicios higiénicos y corrales para la crianza de animales domésticos producen dispersión de agentes contaminantes hacia los túmulos.

Descripción de la excavación. Las dimensiones del túmulo 1 donde se tomaron las muestras son de 2,30 m de altura y $35 \mathrm{~m}$ de diámetro. La excavación de una trinchera de $18 \mathrm{~m}^{2}$ mostró siete capas de fibra vegetal y ocho capas de áridos, estas últimas formadas por fragmentos de roca ingnimbrítica y arena. A lo largo de toda la excavación, y en la mayoría de los estratos, especialmente los que eran contiguos a una capa vegetal o en la capa vegetal misma, se encontraron piedras de grandes dimensiones ubicadas sobre las capas de fibra vegetal. Al parecer fueron depositadas en el túmulo de manera estratégica, como soporte para moldear y sostener a la estructura, así como una manera de delimitar las distintas capas vegetales y capas de material árido. Asociadas a estas piedras en el estrato 6 se hallaron restos de tejidos y algunas osamentas humanas, lo que indica que probablemente fue una tumba removida, ya que sobre estas evidencias se halló una capa de fibra vegetal.

En el estrato 7 correspondiente a una capa vegetal se encontró la presencia de troncos puestos dentro de la capa de fibra vegetal, estos troncos fueron utilizados como soportes sobre los que se estructuró la capa de fibra vegetal, es decir, formó parte de la estructura basal, también es probable que sirviera como indicador o marcador de tumbas, sin embargo no se hallaron evidencias de osamentas humanas.

En los estratos 2 y 3 de material árido se hallaron restos de carbón, sin asociación a osamentas humanas o a un contexto ritual determinado (quema de plantas), probablemente fueron depositados como consecuencia de quemas hechas fuera de la construcción del túmulo (Figura 4).

Si bien los túmulos de Az-24 constituyen una sola unidad, fue posible determinar cuatro unidades monticulares adosadas entre sí (Figura 5). El túmulo 1 fue construido con material árido de consistencia compacta, se observa en la preparación de las camadas el uso intensivo de la especie vegetal cola de caballo (Equisetum fluviatilis L.), conformando gruesos estratos. También se observan troncos y ramas gruesas que ocupan la totalidad del área de túmulo.

\section{Estudios geofísicos en el sitio Az-24}

El trabajo consistió en el estudio con gradiente magnético y con georradar. En el costado poniente del túmulo, dos perfiles expuestos mostraron la estructura conformada por capas de fibra vegetal y capas de tierra superpuestas una sobre otras en forma alternada con algunas rocas. En el costado oriente del túmulo se tienen algunas construcciones precarias, con materiales sencillos como madera y telas, que impidieron el estudio de esta parte del sitio (Figura 6).

Se realizaron dos retículas de gradiente magnético. La primera de 20 × 20 m se localizó en el faldeo norte y abarcó la cima del túmulo (Figura 7). En dicha área están los testimonios de los perfiles de las cuadrículas F.3 y F.5 excavadas el 2009 y donde se obtuvieron muestras para fechado por radiocarbono, arrojando fechas que oscilan entre el 200 y 400 a.C. (Muñoz et al. 2014). La segunda retícula de 20 × $30 \mathrm{~m}$ se ubica en los faldeos del túmulo, sector oeste, donde se han encontrado tumbas construidas debajo del piso a manera de fosas, vinculadas al período Medio (500 al 700 d.C.) (Muñoz 2012).

Descripción de resultados. En el mapa de gradiente magnético se representan los dipolos producidos por la presencia de rocas volcánicas magnéticas. Cada roca tiene un polo positivo representado en color rojo y un polo negativo en color azul (Figura 8). En donde los colores se hacen más intensos la amplitud de la magnetización es mayor y marca zonas en donde las piedras se pueden concentrar. Un antecedente del análisis de dipolos magnéticos en sitios arqueológicos fue la exitosa aplicación de esta 


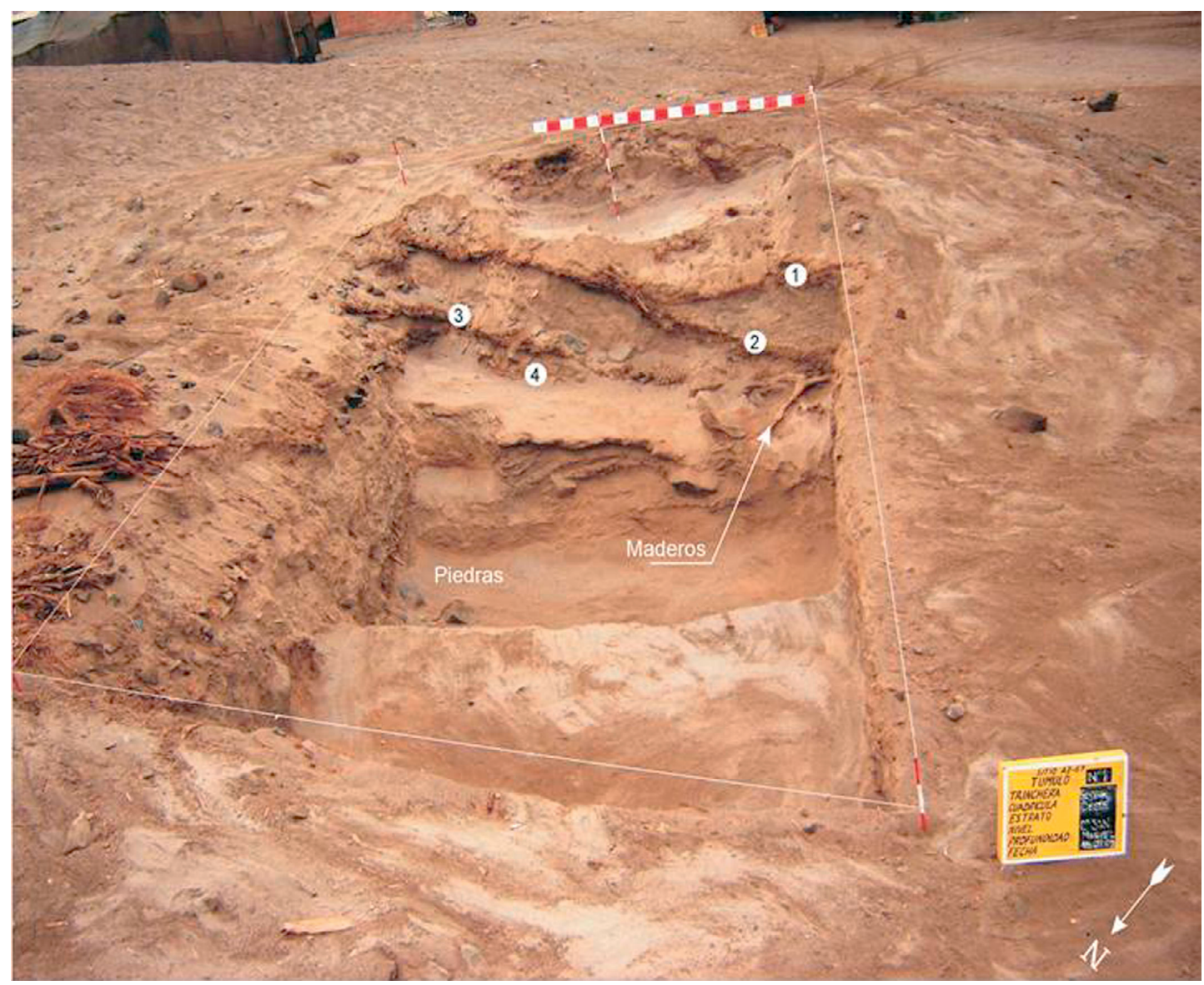

Figura 4. Excavación en el túmulo 1 del sitio Az-24.

Excavation in mound 1 at site Az-24.

técnica en Loma Alta, Zacapu, Michoacán (Hesse et al. 1997). En particular en la zona estudiada alrededor de los túmulos, donde los materiales constructivos principales son tierra y restos vegetales, la presencia de anomalías magnéticas es algo distintivo y registra la posición de las rocas ignimbríticas traídas de los alrededores y concentradas en espacios particulares y con propósitos definidos. En el hemisferio sur, en los casos en que la mancha roja se encuentre inmediatamente al norte de la mancha azul, se puede presumir la existencia de magnetismo termorremanente y en consecuencia de un espacio que ha sido sometido a calentamiento. Esto en ocasiones detecta la presencia de hornos, hogueras y fogones.

El mapa de gradiente magnético en la parte sureste (E340-360, N300-320) muestra alineamientos de rocas aproximadamente al centro de la retícula que semejan una "Y" abriendo hacia el norte. Se aprecia también al centro del límite oeste un dipolo intenso además de algunos patrones de menor intensidad que en este momento no pueden interpretarse. En la retícula ubicada al noroeste se aprecia con claridad un arco (E310-340, N320-326) que abre hacia el norte y que tiene más de $20 \mathrm{~m}$ de longitud en el extremo sur de las retículas. En la parte sureste del arco se encuentra una gran concentración de rocas acomodadas, mientras que al suroeste se observa la misma trayectoria curvada con otro tipo de material magnetizado, pero sin rocas, debido a la ausencia de dipolos bien definidos y a su forma alargada. Existen además tres dipolos que pueden ser producto del calentamiento de la superficie donde son registrados.

Como se ha comentado, el hallazgo de las rocas implica que fueron traídas y depositadas en el túmulo como parte de alguna manifestación ritual, como por ejemplo la preparación de un entierro. 


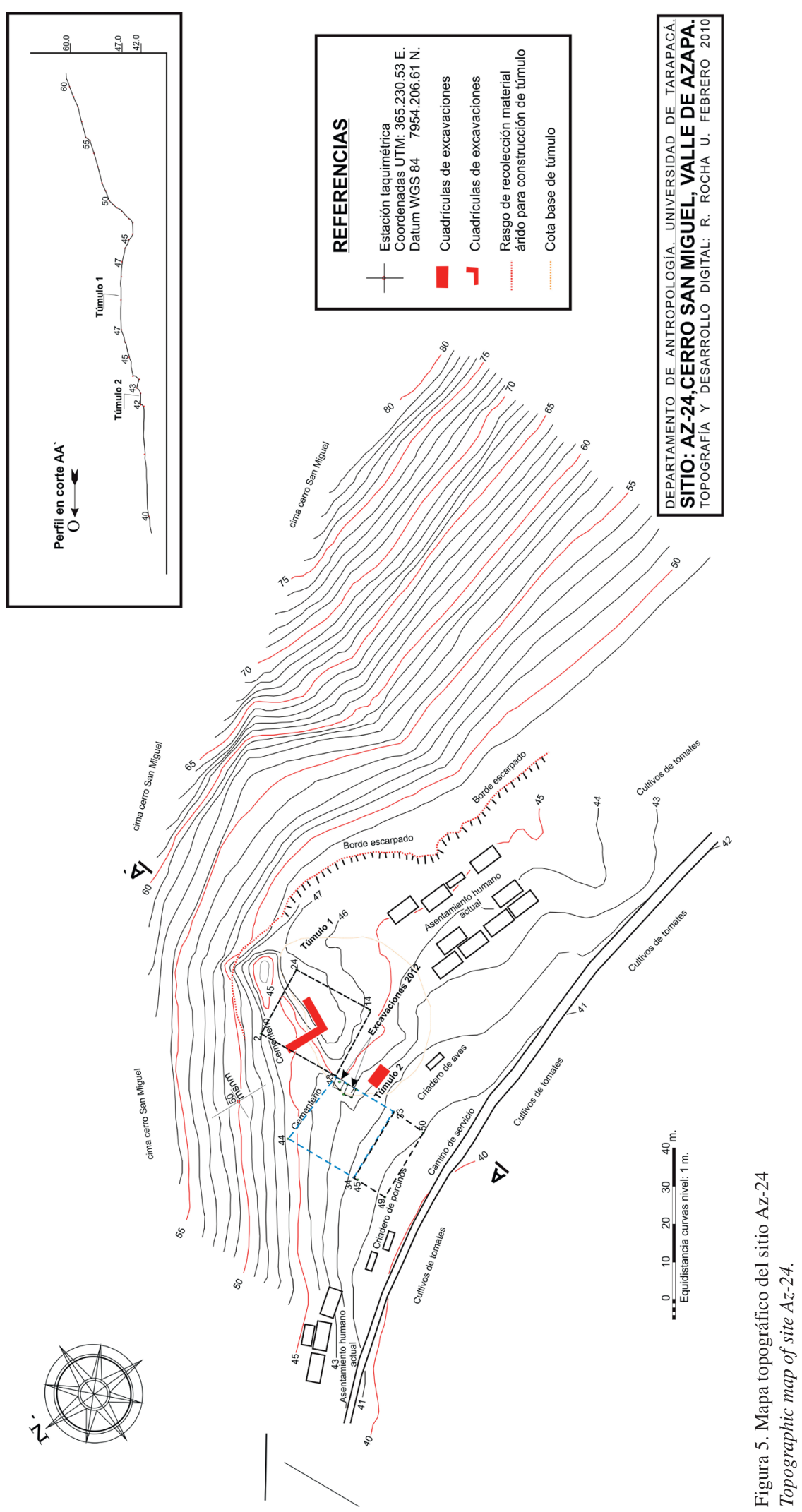




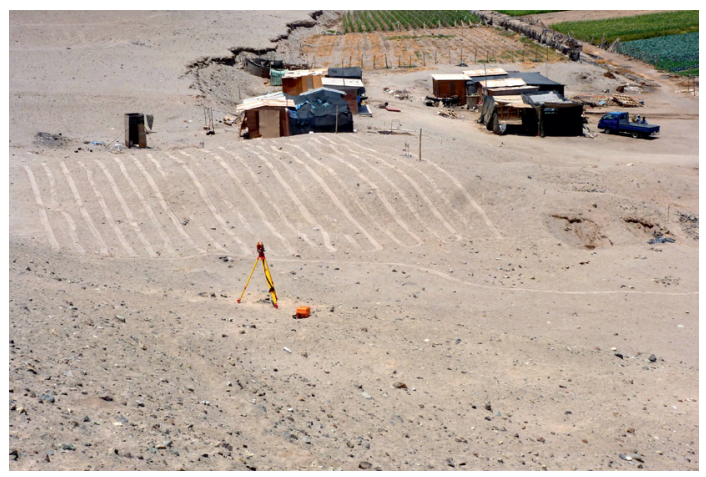

Figura 6. Vista general del sitio Az-24. Se observan los pozos excavados, las casas habitadas actualmente y la retícula norte marcada por el paso de la antena del radar.

General view of site Az-24. It is possible to observe the excavated areas, the currently inhabited houses and the north grid marked by the tracks left by the georadar antenna.

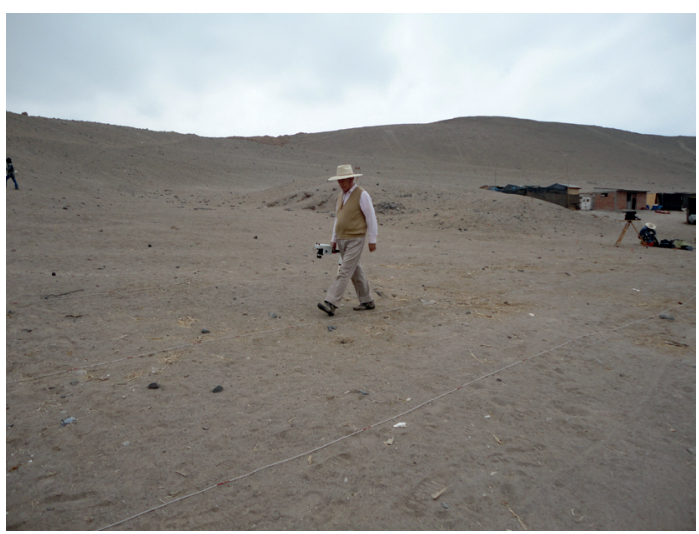

Figura 7. Levantamiento de gradiente magnético en Az-24. Magnetic gradient survey in Az-24.

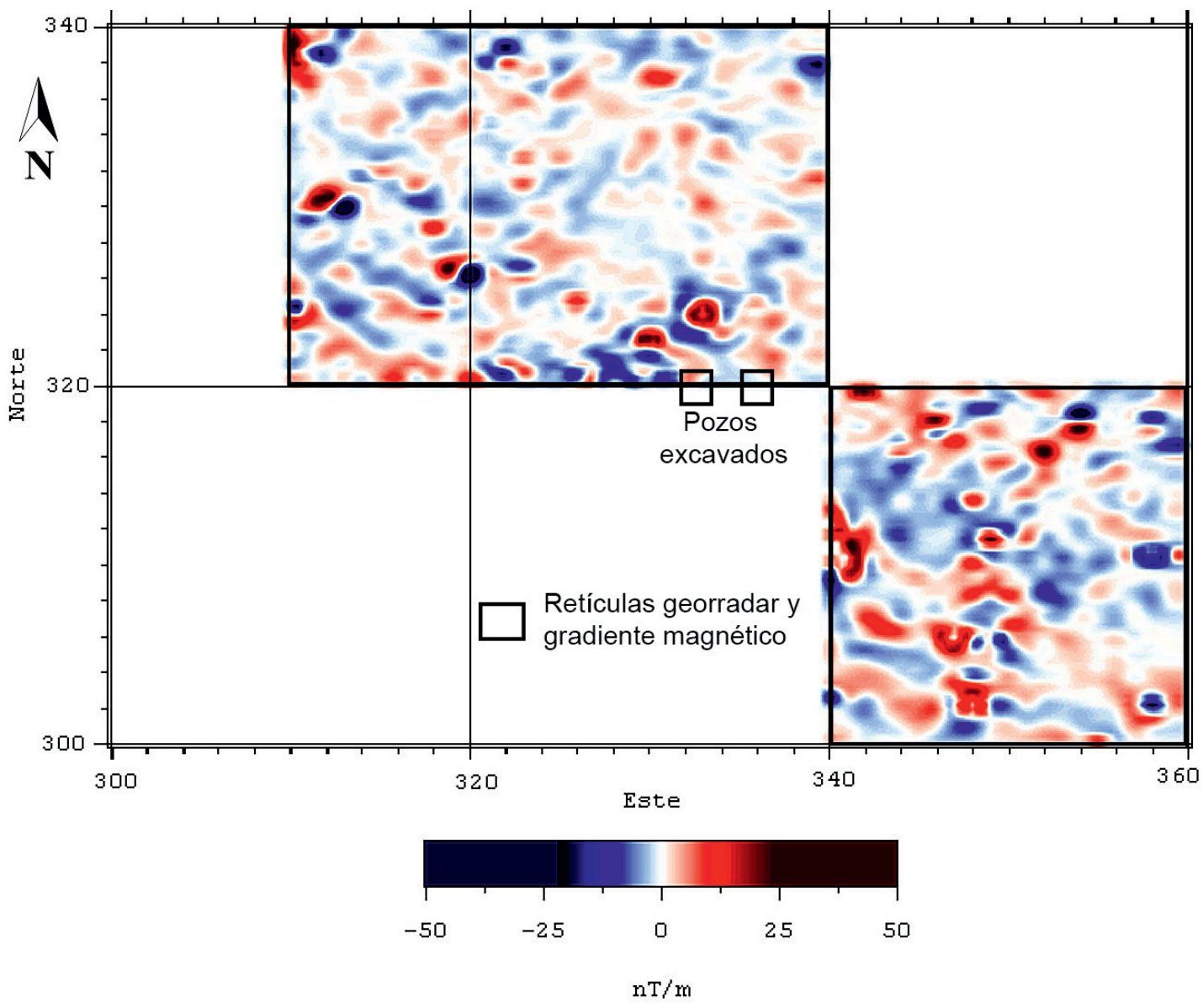

Figura 8. Mapa de gradiente magnético del sitio Az-24.

Magnetic gradient map of site Az-24. 
En la imagen se pueden interpretar al menos dos alineamientos intencionales de roca que pudieran quizá definir un tipo de construcción funeraria. Esto se relaciona con la presencia de los dos pozos excavados un poco al sur de la posición de las rocas que forma el arco.

En las mismas retículas estudiadas con gradiente magnético se levantaron líneas con el georradar para contrastar los datos proporcionados por cada técnica, se utilizó una antena de $400 \mathrm{MHz}$ y con una separación entre líneas de $1 \mathrm{~m}$ (Figura 9).

La retícula de georradar noroeste fue la que mejor se interpretó al presentar menor distorsión por la topografía del terreno. Los cortes de profundidad del georradar son producto del procesamiento conjunto de los datos obtenidos sistemáticamente en líneas paralelas. El acomodo de los perfiles permite generar un espacio tridimensional que al final puede cortarse generando una superficie horizontal a la profundidad seleccionada (Figura 10). El corte a $1 \mathrm{~m}$ de profundidad muestra una clara correspondencia entre los dipolos magnéticos que se encuentran entre E330-334 y N330-324 con una banda de reflexiones intensas marcadas en color rojo sobre el fondo verde, lo que indica la presencia de un conjunto de rocas que, además de sus propiedades magnéticas, se encuentran a $1 \mathrm{~m}$ de profundidad y pudieron reflejar las ondas electromagnéticas. En el mapa magnético esta trayectoria curva tiene continuación, pero en los cortes de profundidad no se aprecia, esto sugiere que en la mitad suroeste de la trayectoria no se utilizaron rocas debido al poco contraste entre materiales, lo que genera menor potencia reflectiva.

Adicionalmente, el corte muestra un conjunto de reflexiones fuertes en la parte noreste de la

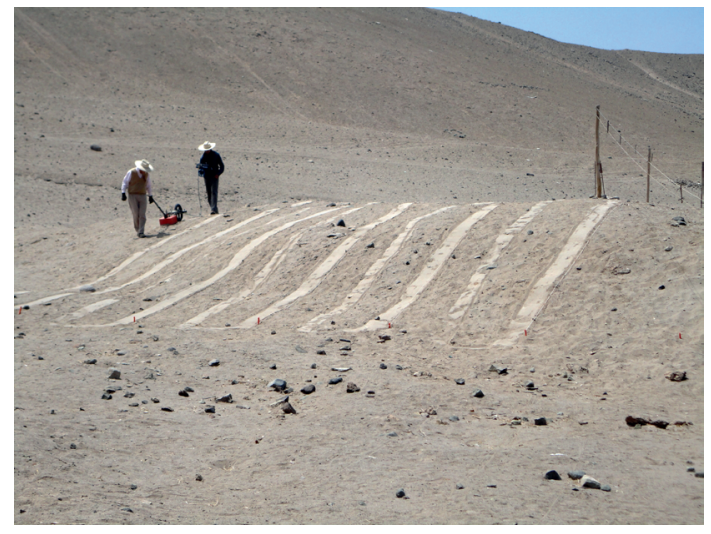

Figura 9. Adquisición de datos de radar en la retícula noreste, sobre el túmulo. La separación entre líneas es de un metro. Georadar data acquisition in north-western grid on the mound. Distance between lines is one meter.

retícula (E330-334 N334-340) y (E336 N330) que no tienen correspondencia evidente con el mapa magnético, esto sugiere una modificación antrópica que no utilizó roca magnética o bien es una zona con enterramientos debido a la presencia de materiales con alto contraste dieléctrico que producen anomalías hiperbólicas similares a las registradas en playa Miller en donde hay evidencia probada de este tipo de reflexiones. La forma de estas anomalías y el contexto en el que se encuentran permite interpretarlas como posibles entierros y se observan mejor en los radargramas individuales de las líneas levantadas en estos lugares.

Como se mencionó en la interpretación del mapa magnético esto representa una actividad humana que transporta materiales y los acomoda siguiendo decisiones conscientes que pueden obedecer a rituales comunitarios relacionados con la muerte.
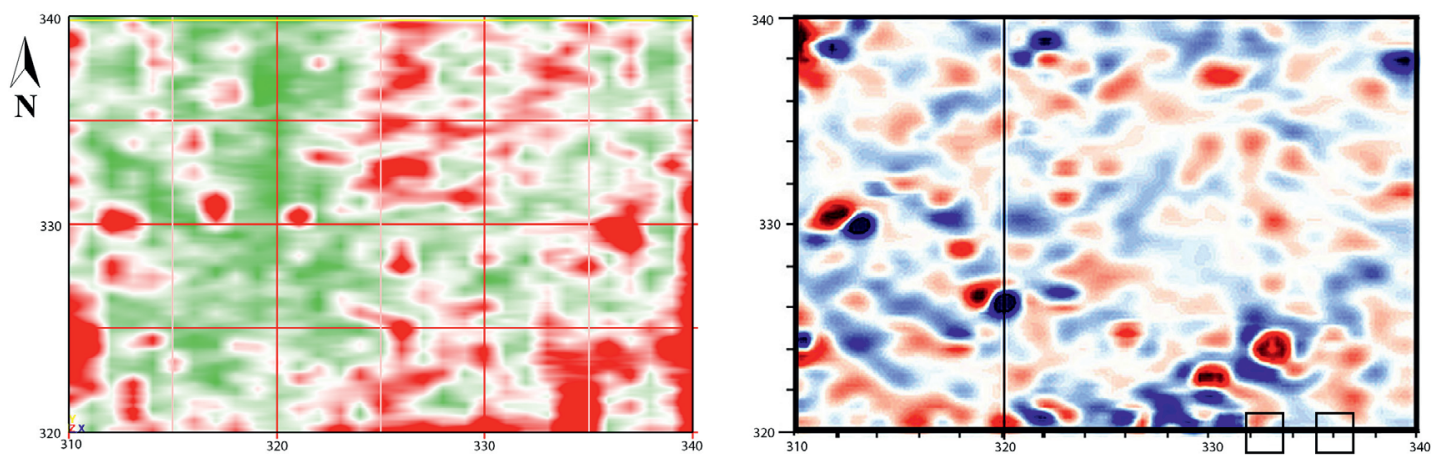

Figura 10. Cortes de profundidad de georradar a $1 \mathrm{~m}$ (izquierda) y módulo de gradiente magnético (derecha).

Georadar depth-slice at $1 \mathrm{~m}$ (left) and magnetic gradient grid (right). 


\section{Análisis de radargramas individuales en Az-24}

Los radargramas son representaciones en perfil de las líneas con georradar levantadas sobre el terreno. La imagen se forma con las reflexiones obtenidas a distintos tiempos (o profundidades) y con la distancia recorrida sobre el terreno. Se representan según sea la tabla de color elegida, para este caso las reflexiones bipolares en color gris y blanco son las más reflectivas (mayor contraste dieléctrico) y las reflexiones en color rojo y negro son menos reflectivas (menor contraste dieléctrico). En el mapa de gradiente se muestran la posición de algunas líneas adquiridas en lugares significativos de los sectores noroeste y sureste (Figura 11).

La línea F216 corta el extremo del arco mostrado en el mapa magnético y confirma la presencia de rocas en los primeros $5 \mathrm{~m}$ del recorrido, pero más interesante resulta la reflexión a los 17,5 $\mathrm{m}$ del recorrido de la antena que tiene una sutil correspondencia magnética y que muestra un material distinto, asociado con lo que parece un espacio rectangular con pisos y elementos entre 0,5 y $1,5 \mathrm{~m}$ de profundidad (Figura 12).

El radargrama de la línea F219, paralela y $3 \mathrm{~m}$ al este de la F216, registra las rocas en los primeros $6 \mathrm{~m}$, pero ahora más dispersas. También muestra una reflexión importante a un metro de profundidad y en $10 \mathrm{~m}$ del recorrido de la antena, la que puede corresponder con un entierro. Tiene correspondencia con la línea anterior, ya que a los $18 \mathrm{~m}$ encuentra una reflexión semejante (Figura 13).

En la retícula ubicada al sureste el radargrama de la línea F171 está modificado con datos topográficos aproximados para ajustar la deformación ocasionada por el relieve del terreno. En el límite sur de la retícula

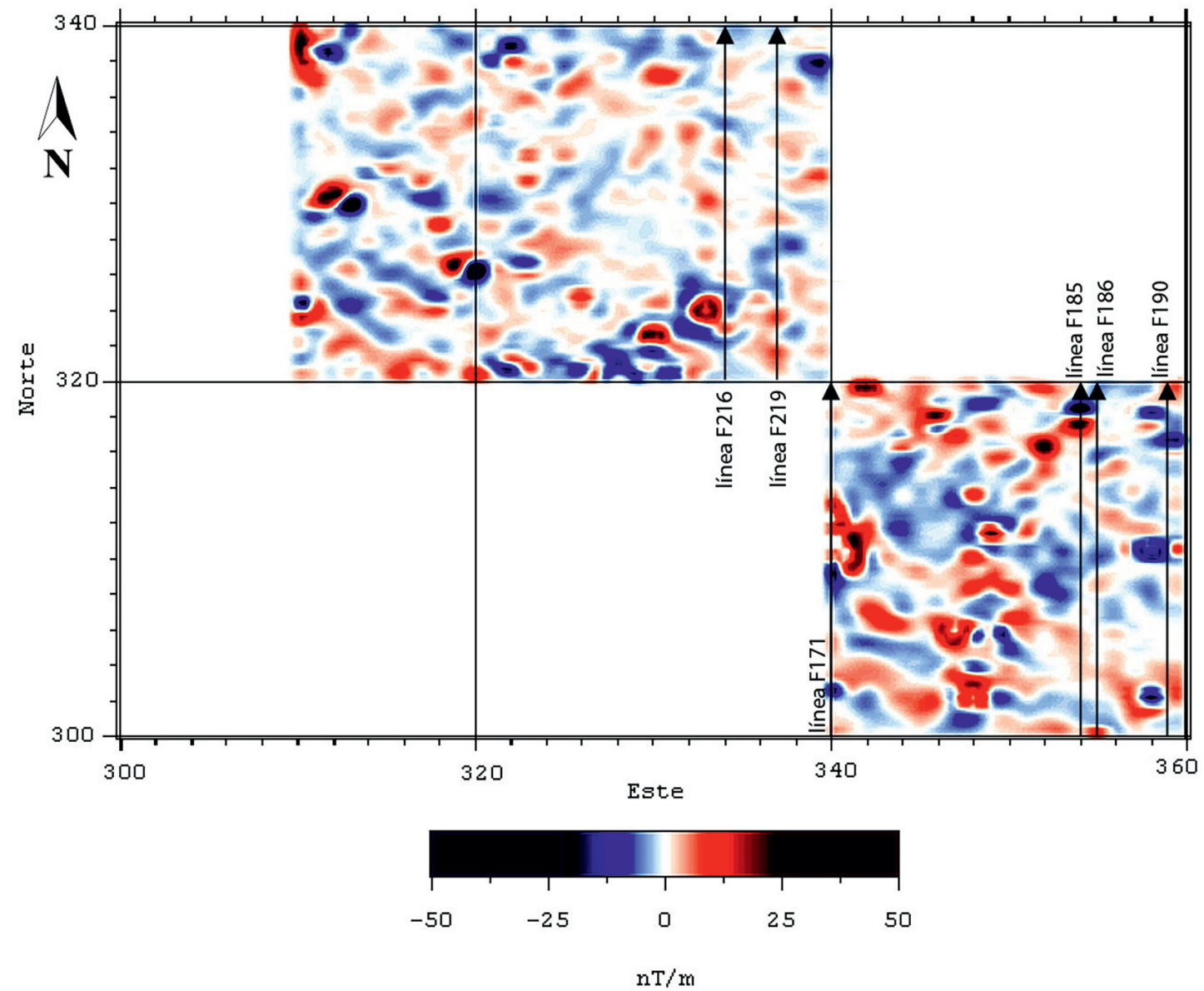

Figura 11. Mapa del gradiente magnético con las líneas de radar marcadas en Az-24. Magnetic gradient map with georadar lines in Az-24. 


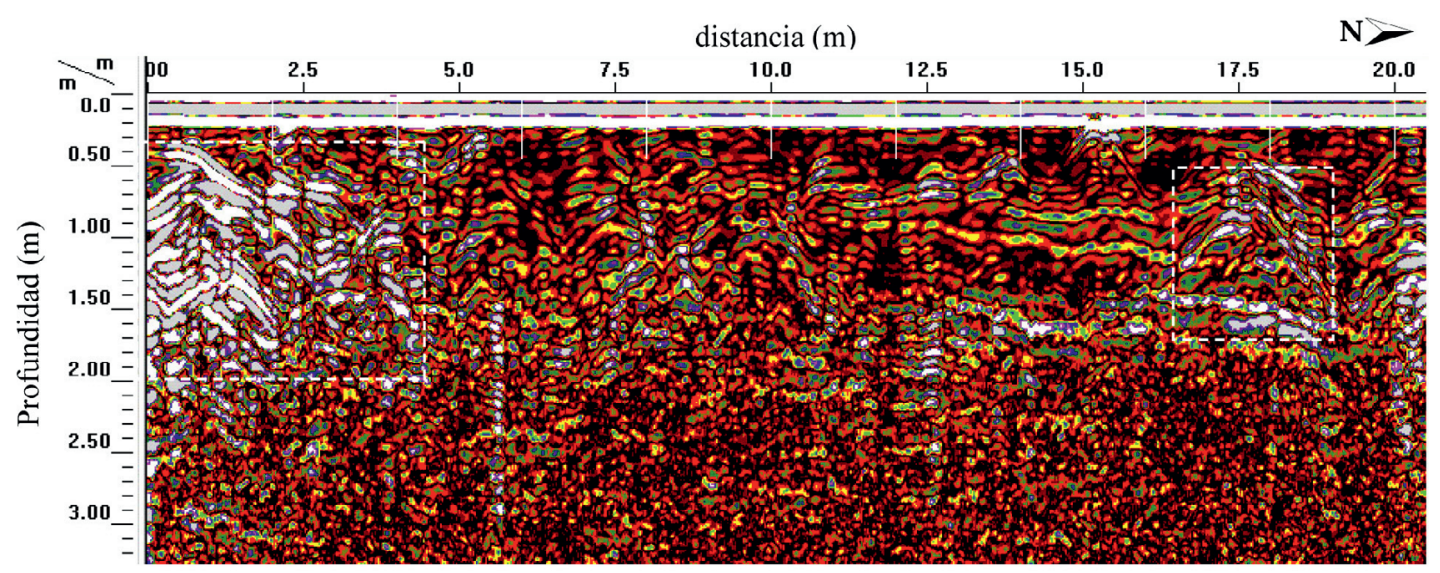

Figura 12. Radargrama de la línea F216.

Radargram line F216.

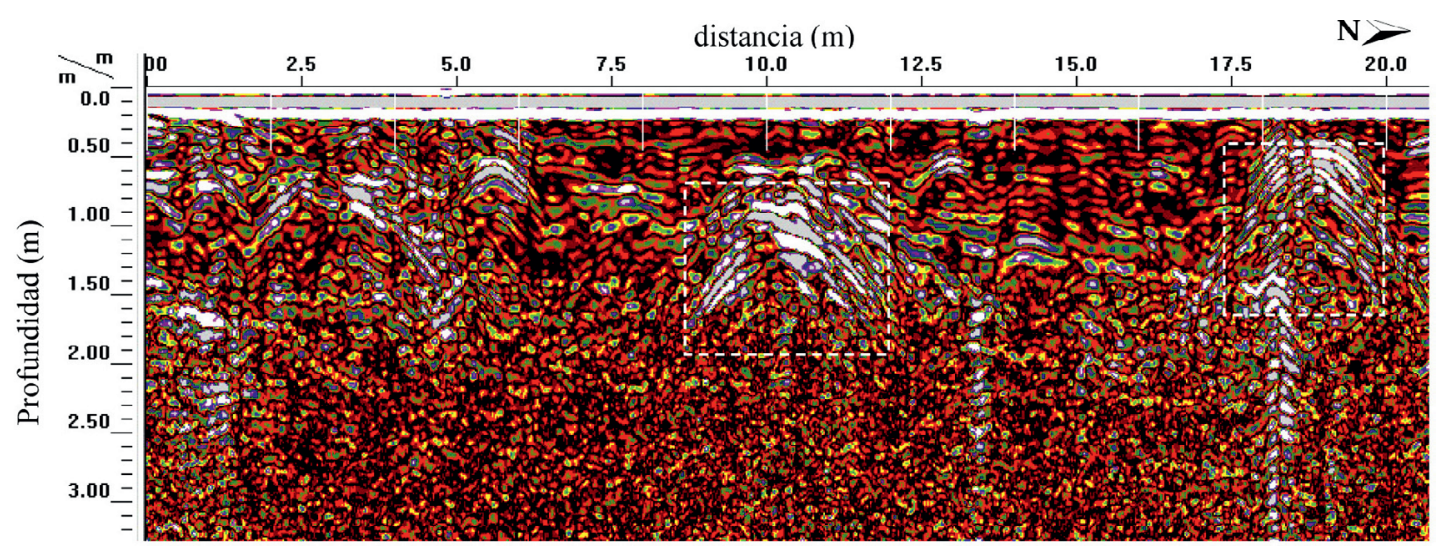

Figura 13. Radargrama de la línea F219.

Radargram line F219.

sureste muestra en los primeros $3 \mathrm{~m}$ de recorrido una reflexión inclinada producto de algún acomodo de material en el límite occidental del túmulo. Pero más interesante son las dos reflexiones entre 5 y $12 \mathrm{~m}$ del recorrido de la antena que muestran dos capas interiores del túmulo que representan etapas constructivas previas. La capa superior muestra entre 12 y $15 \mathrm{~m}$ una superficie horizontal en la parte norte del túmulo. Aproximadamente en 13 m se observa una reflexión múltiple que debió ser ocasionada por la presencia de algún fragmento de metal en la superficie (Figura 14).

La línea F185 muestra una clara reflexión que no es registrada por el gradiente magnético a los $10 \mathrm{~m}$ de recorrido y aproximadamente a $1 \mathrm{~m}$ de profundidad, sin embargo, entre 17,5 y $19 \mathrm{~m}$ del recorrido de la antena se registra una reflexión aún más amplia que coincide con un dipolo magnético de un posible acomodo de piedras. En 19 m podría ser un objeto metálico (Figura 15).

Para la línea F186 a un metro de distancia de la anterior es notablemente distinta. No tiene correspondencia directa con anomalías magnéticas, pero muestra una gran cantidad de reflexiones. La más destacada se encuentra a $14 \mathrm{~m}$ del recorrido de la antena y a $0,6 \mathrm{~m}$ de profundidad y por la forma podría asociarse con un entierro. Los primeros 10 $\mathrm{m}$ del recorrido muestran una reflexión continua descendente que deberá corresponder con una superficie aproximadamente horizontal tomando en cuenta la topografía. Esto debe ser una etapa constructiva anterior del túmulo (Figura 16).

Hacia el este de la retícula se encuentra la línea 190 y registra reflexiones importantes en los primeros 


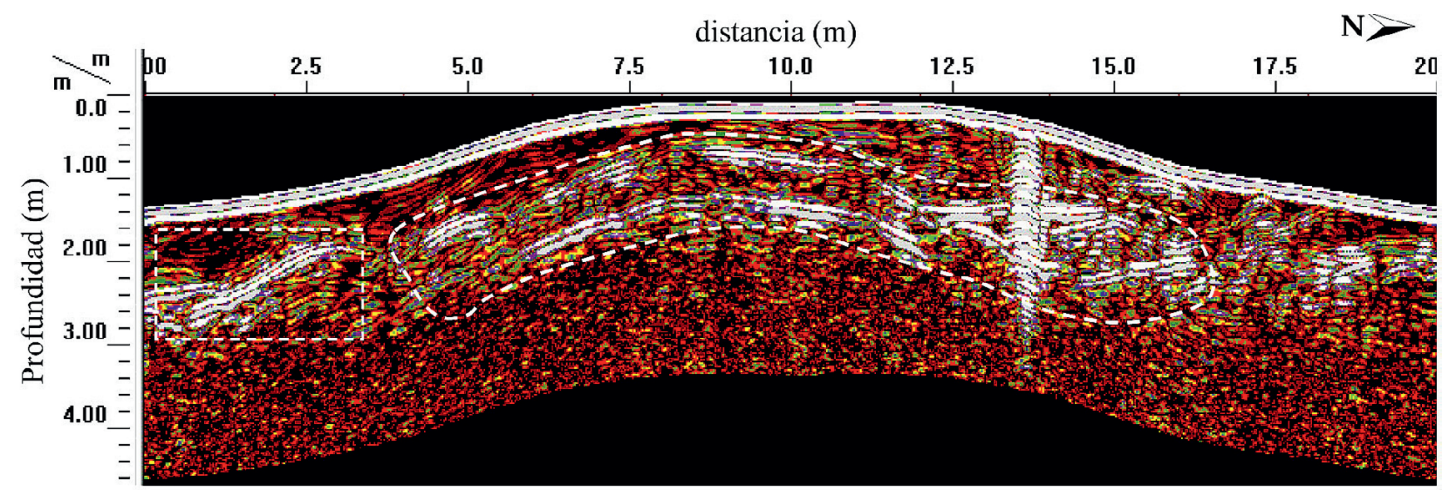

Figura 14. Radargrama de la línea F171.

Radargram line F171.

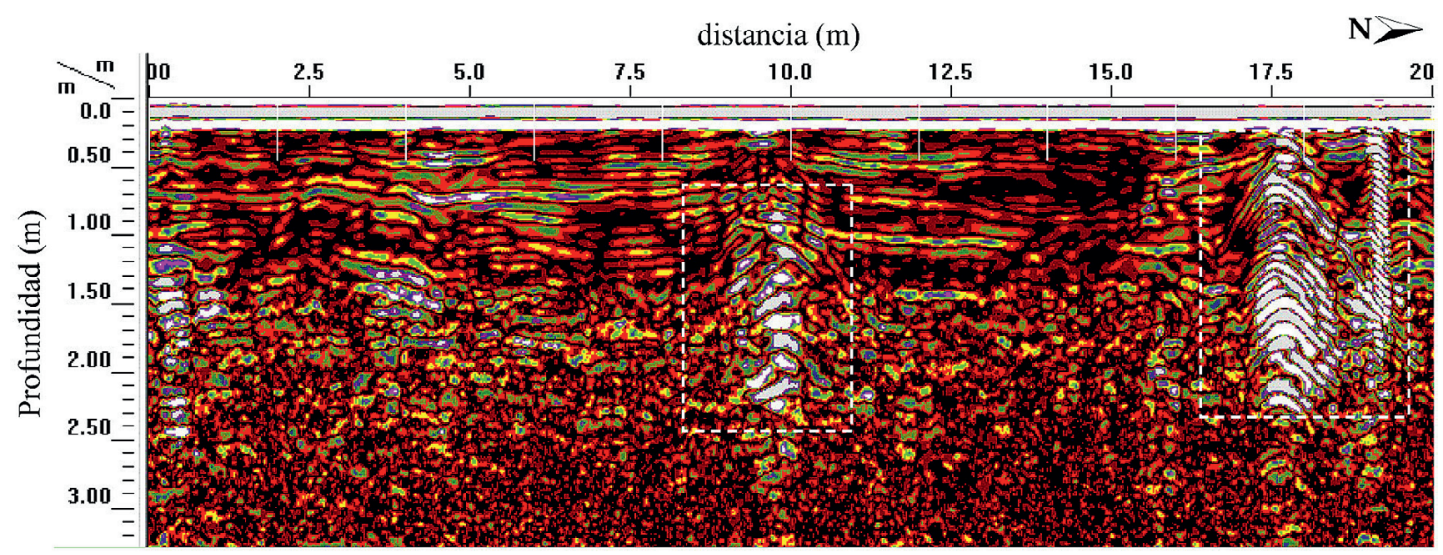

Figura 15. Radargrama de la línea F185.

Radargram line F185.

$8 \mathrm{~m}$ del recorrido. Destaca la reflexión en $2 \mathrm{~m}$ de recorrido y a 1,10 $\mathrm{m}$ de profundidad. También en 6 $\mathrm{m}$ del recorrido se aprecia una reflexión hiperbólica a $0,7 \mathrm{~m}$ de profundidad. Entre 10 y $14 \mathrm{~m}$ se tienen tres reflexiones superficiales, pero a partir de un metro de profundidad se observa una reflexión múltiple posiblemente de un objeto metálico o de un relleno con materiales arqueológicos (Figura 17).

Podemos decir que la información que proporcionaron los estudios magnéticos y de georradar corrobora el uso de fragmentos de rocas como cantos rodados en la construcción de estos monumentos de tierra y fibras vegetales y por lo tanto están dentro de la lógica constructiva de los túmulos. Hay que destacar que la distribución de rocas no es aleatoria ni uniforme, sino que se concentra en algunas áreas, pero además se han podido observar posibles etapas constructivas previas en algunos de los túmulos estudiados que no siguen la forma que ahora apreciamos. Algunas de las reflexiones hiperbólicas aisladas sugieren la presencia de bultos y ofrendas voluminosos a cierta profundidad que pudieran ser producto de actividades rituales, y de preparación de tumbas de los antiguos constructores de los túmulos.

\section{Complejo de Túmulos Az-80}

Ubicación geográfica y descripción del túmulo. Los túmulos Az-80 se ubican en la ladera sur del valle de Azapa, en el vértice noreste de la terraza de origen fluvial denominada Pampa de Alto Ramírez. Los 21 túmulos identificados se distribuyen en una extensión de $115 \mathrm{~m}$ a partir de una colina en el extremo sur y $66 \mathrm{~m}$ de este a oeste, se incluyen en dos posibles conglomerados referenciados como sectores sur y norte. El sector sur incluye ocho montículos de baja altura que no superan $1,50 \mathrm{~m}$ 


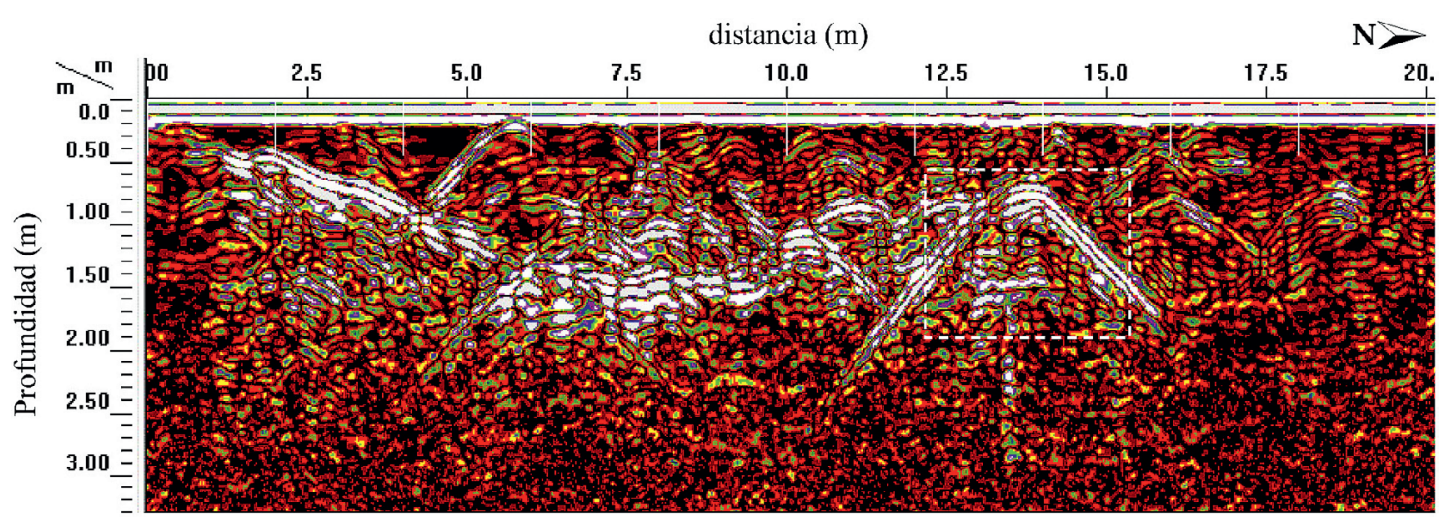

Figura 16. Radargrama de la línea F186.

Radargram line F186.

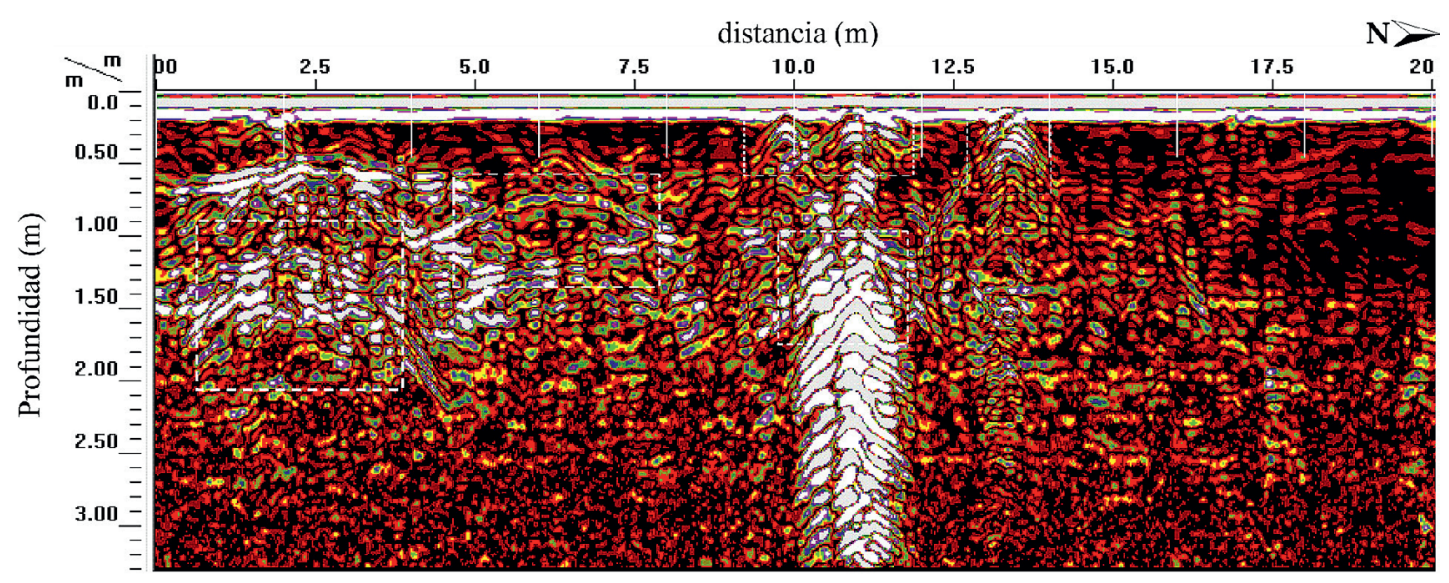

Figura 17. Radargrama de la línea F190.

Radargram line F190.

manteniendo pequeños márgenes de separación entre ellos. En el sector norte se concentran los de mayores dimensiones fluctuando alturas entre 3 y $4 \mathrm{~m}$ y superando los $20 \mathrm{~m}$ de diámetro. Asociado a este conjunto de túmulos hallamos un cementerio muy alterado correspondiente al período Medio (Figura 18).

El túmulo excavado corresponde al número 1, forma parte de una cadena de túmulos construidos, adosados unos con otros, con vías de desplazamiento. Presentan homogeneidad en su altura y volumen. Su estructura está conformada por estratos áridos gruesos intercalados con estratos vegetales de fino espesor.

Estado de conservación del sitio. Los túmulos presentan serios problemas de conservación, ya que a su alrededor fue trazado un camino vehicular, además lo atraviesan un cerco perimetral de una parcela y una línea de postes construida para la energía eléctrica comunitaria. Sin embargo, el mayor deterioro se produce por la edificación de invernaderos, vertederos de cosechas y tecnología agrícola, una red de riego por aspersión y goteo que amplía el efecto de la humedad a la estratigrafía arqueológica expuesta, además de galpones para maquinaria y de empaque.

Descripción estratigráfica del túmulo excavado. El túmulo 1 tiene una altura de $4 \mathrm{~m}$ y un diámetro de $16 \mathrm{~m}$. Se excavó una trinchera de $12 \mathrm{~m}^{2}$. De acuerdo con el perfil excavado las capas de fibra vegetal fueron cuatro y las capas de árido cinco. Las capas de fibra vegetal tienen espesores de 10 a $16 \mathrm{~cm}$, están conformados por restos de plantas de especies nativas (chilca, chañar, totora, pajonal y restos de maderas de molle y yaro). 


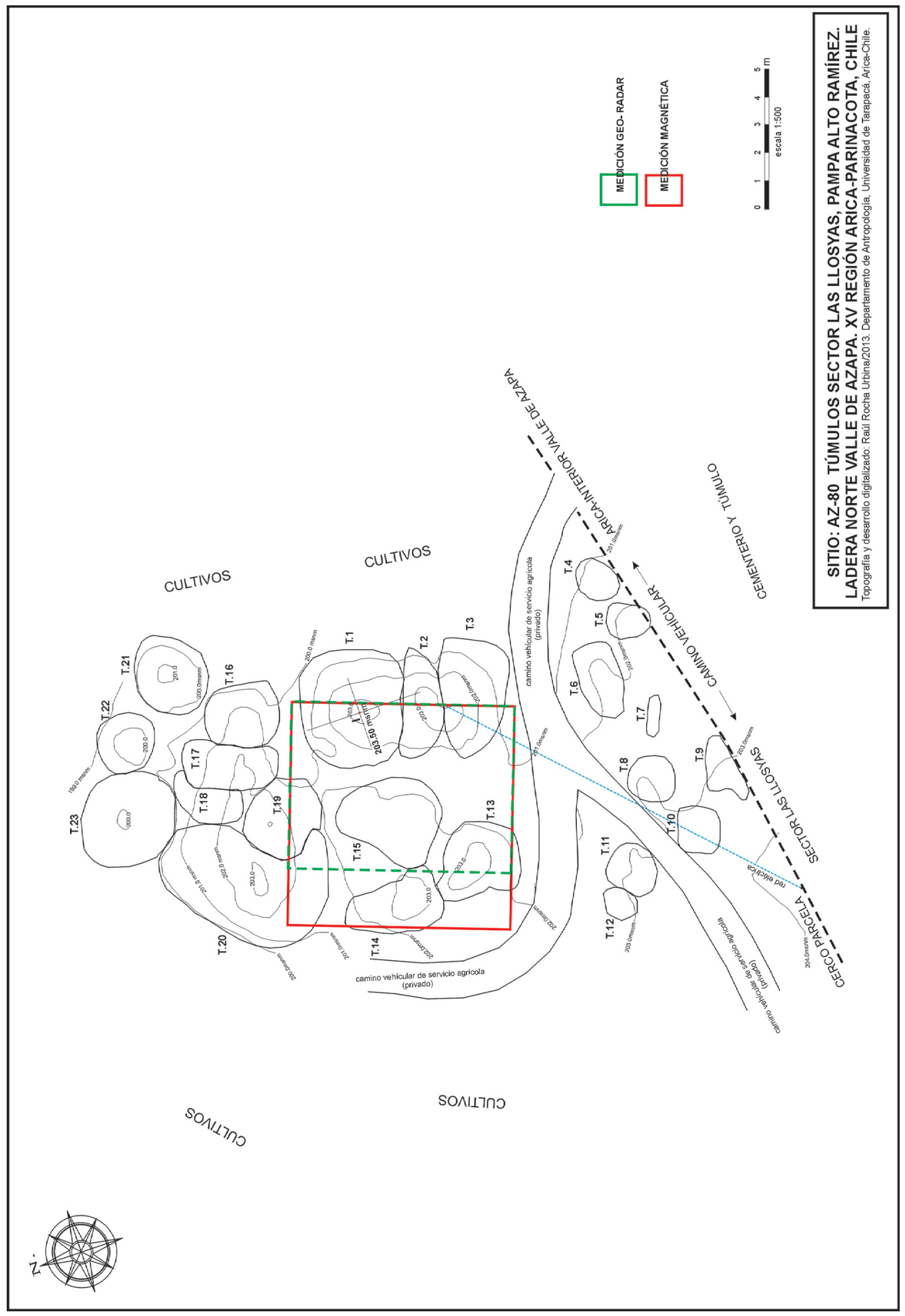


Las capas de material árido, su composición está basada en tierra y arenilla color gris, susceptible a erosión por acción de viento. Eventualmente se observan piedras de regular tamaño. En esta excavación no se registraron restos humanos ni ofrendas. Solo se pudo observar algunas piedras de gran tamaño puestas sobre las camadas de fibra vegetal. Las muestras datadas mediante carbono 14 van desde el 500 al 200 a.C. (Muñoz et al. 2014).

\section{Estudios geofísicos en el sitio Az-80}

El estudio comprendió cuatro retículas de gradiente magnético que alcanzan un cuadrado de 40 x 40 m orientado de norte a sur. La posición de la retícula incluyó el barrido superficial de los túmulos 1 y 4 , incluyendo un perfil expuesto producto de excavaciones realizadas el 2008 (Figura 19). La estratigrafía es distinta a la de los túmulos de Az-24, ya que en el corte observamos una mayor proporción de enramados que de totora (casos anteriores), además de una menor cantidad de rocas (Muñoz 2012).

El mapa de gradiente magnético muestra algunas interferencias debidas a instalaciones modernas, debido a que se localizaron en la parte noroeste del terreno zonas quemadas con basura metálica que claramente aparecen como una gran alteración en esta parte del mapa magnético (Figura 20). Otro dato interesante es que sobre los montículos casi no hay anomalías dipolares, lo que confirma la observación de que la roca que podría formar parte de sus capas alternadas con ramas es muy poca o bien, si hubiera, no tienen propiedades magnéticas. Las anomalías

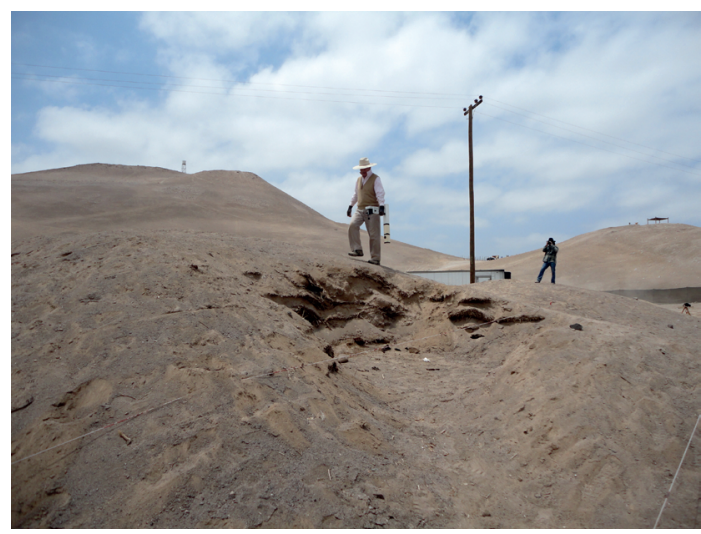

Figura 19. Adquisición de datos magnéticos sobre el perfil del área excavada en 2008.

Magnetic gradient data acquisition over the profile of area excavated in 2008.

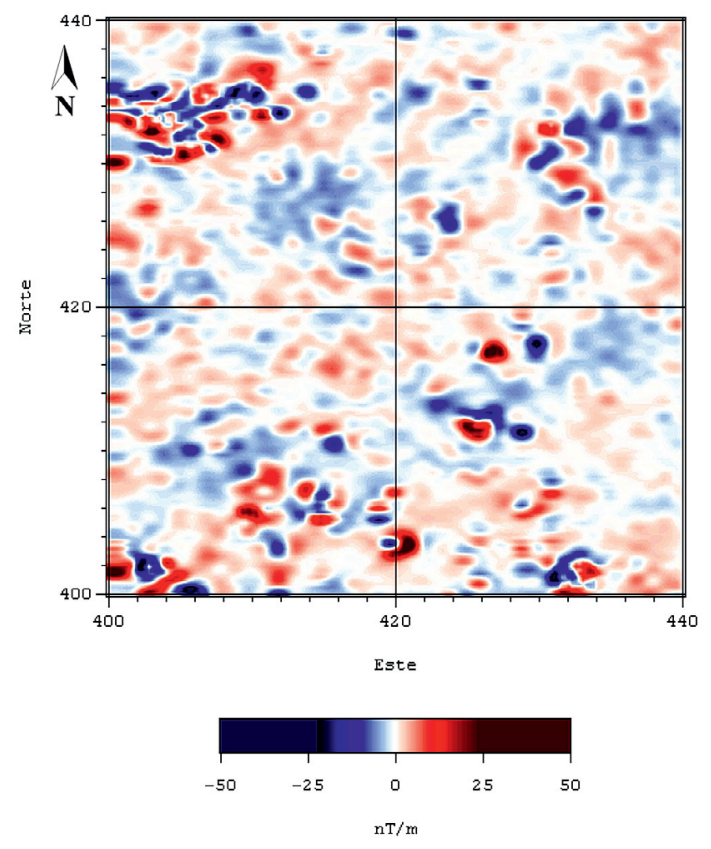

Figura 20. Mapa de gradiente magnético del sitio Az-80. Magnetic gradient map of site Az-80.

magnéticas se ubican siguiendo aproximadamente el perímetro de la base de los túmulos. Muchas de ellas parecen rocas acomodadas en la ladera o falda del túmulo y parecería que algunas de las rocas detectadas están directamente relacionadas con los pozos de saqueo que se encontraron en la superficie.

El trabajo con el georradar se realizó en las mismas retículas que se hicieron los estudios magnéticos. A causa de que la parte noroeste del mapa magnético mostraba gran cantidad de basura moderna se decidió acortar $10 \mathrm{~m}$ para estudiar con radar solo un área de 30 x $40 \mathrm{~m}$. Durante el estudio se observó directamente en la pantalla del georradar que la parte alta de los montículos casi no presentaban anomalías, en cambio la parte baja, entre los montículos, es donde más se localizaron anomalías hiperbólicas que podrían estar indicando posibles intrusiones o enterramientos (Figura 21).

Con la finalidad de ubicar las anomalías que se registraban con el georradar se decidió realizar un croquis de la ubicación de los túmulos y marcar con una $\mathrm{X}$ la posición de las reflexiones más evidentes, así como de las zonas de excavación, saqueos, ubicación de cables eléctricos que corre por el suelo y algunas rocas superficiales. El croquis no es un levantamiento topográfico, es solo un registro aproximado de las condiciones de la superficie del 


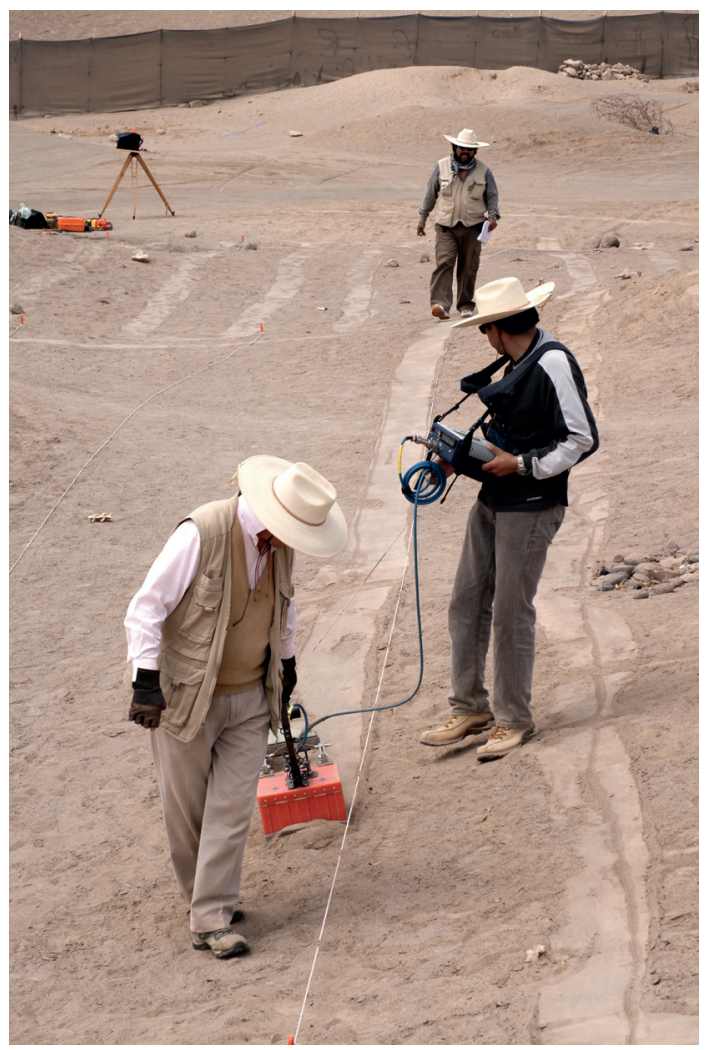

Figura 21. Adquisición de datos de radar en el sitio Az-80. Las líneas marcadas por el paso de la antena sobre el terreno tienen un metro de separación y están dirigidas al Norte.

Georadar data acquisition at site Az-80. Lines marked by the antenna on surveyed area have a one meter separation and are oriented towards the North.

terreno para ayudar en la interpretación de los datos obtenidos (Figura 22).

La Figura 23 muestra la correspondencia del croquis (en verde) y el mapa magnético (en negro), superpuestos en el mapa de los túmulos relevado por Muñoz et al. (2013). En el módulo sureste (N400-420 E420-440) se observó una correspondencia entre los dipolos magnéticos y algunas de las reflexiones marcadas con $\mathrm{X}$, mientras que en el módulo noreste (N420-440 E420-440) esta correspondencia no ocurre. Sin embargo, hay un patrón lineal de reflexiones marcadas con $\mathrm{X}$ que va de la esquina noroeste a la esquina sureste del propio módulo y que parece corresponder aproximadamente a una parte del borde suroeste del túmulo 1 (T1).

Como se comentó, el conjunto de la esquina noroeste corresponde a una concentración de basura moderna en la superficie y no se tomó en

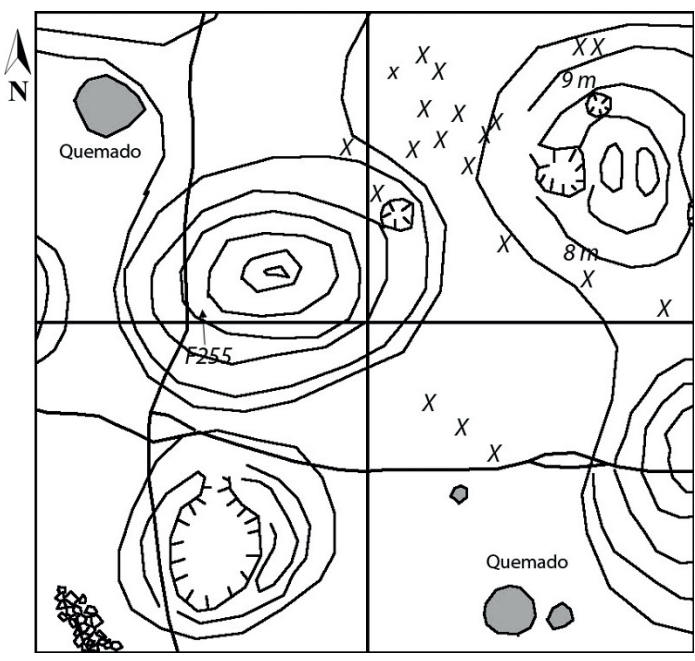

Figura 22. Registro aproximado de los principales elementos encontrados sobre el terreno del sitio Az-80.

Approximate position of the main elements found on the surface of site Az-80.

consideración. Las anomalías magnéticas en la parte noreste están directamente asociadas con uno de los hoyos de saqueo, cerca de la parte alta de uno de los túmulos. Pudieran representar elementos arqueológicos enterrados hechos con piedra que fueron removidos y sus fragmentos expuestos en esta zona.

En la esquina suroeste de la retícula se aprecia otro conjunto de dipolos asociado a otro de los túmulos saqueados y que nuevamente puede tratarse de evidencia arqueológica removida. Por último en la parte sureste y cerca del límite sur de la retícula se aprecia una zona de magnetismo termorremanente que está directamente asociada a una mancha de carbón que se observó en la superficie. Esta junto con otra zona un poco más al norte (N412 E426) muestran dos claras evidencias de magnetización producidas por el calor de una combustión que deberán verificarse.

\section{Interpretación de radargramas en la mitad sur}

Los vectores trazados en el mapa magnético muestran la posición de las líneas realizadas sobre el terreno y que fueron seleccionadas por su mayor contenido de información. Los radargramas individuales están marcados con el número de archivo (File) asignado por el instrumento (Figura 24). 


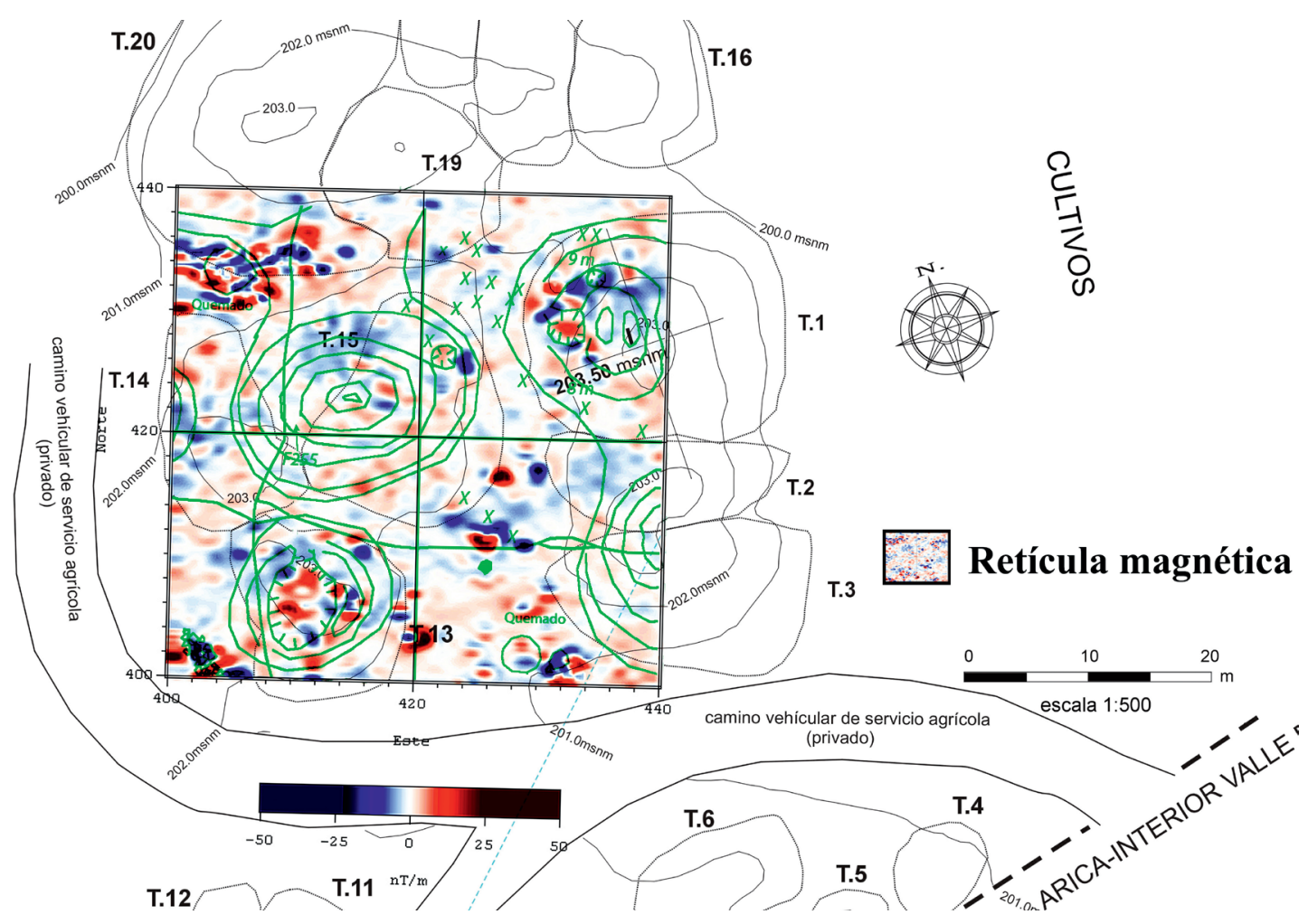

Figura 23. Mapa de gradiente magnético superpuesto al croquis del área registrada. Magnetic gradient map overlapping the sketch of the area studied.

Las líneas F226, F227, F228 y F229 (Figura 25a, b, c, d) cruzan el túmulo saqueado (T13). En sus radargramas se observa que casi no presentan reflexiones superficiales, pero al acercarse a $1,5 \mathrm{~m}$ de profundidad se pueden ver pequeñas reflexiones que se interpretan como rocas. Destaca la base del túmulo mayor al norte (T15) donde se presentan acomodos de materiales que generan reflexiones considerables que por su intensidad sugieren materiales cuya composición contrasta enormemente con los del túmulo. Además aparecen dos reflexiones verticales que parecen delimitar el espacio central del túmulo.

El radargrama de la línea F234 registra algunas reflexiones de rocas superficiales que parecen corresponder a dipolos magnéticos ubicados entre 5 y $10 \mathrm{~m}$ del recorrido, pero al final entre 15 y $20 \mathrm{~m}$ muestra otras reflexiones que sugieren el acomodo de los materiales que dieron forma a la base del túmulo mayor (Figura 26a). La línea F241-273 muestra nuevamente correspondencia entre dipolos magnéticos y reflexiones en los primeros metros (Figura 26b). De la misma forma la línea F242-274 muestra reflexiones que coinciden con anomalías magnéticas y con la línea anterior entre 15 y $20 \mathrm{~m}$ y que claramente muestran la presencia de materiales culturales enterrados (Figura 26c).

La línea F247-279 pasa por el borde de otro túmulo (T3) y muestra el acomodo de las capas que lo forman, sin embargo cuando pasa por el túmulo 1 se observan claramente una mayor cantidad de capas con materiales contrastantes (Figura 27a). La línea F250 pasa cerca de la cima y ofrece una vista de la estratigrafía con capas horizontales que parecen formar perfiles de etapas constructivas anteriores (Figura 27b).

Las líneas F253-285 recorre el límite oriental del área estudiada. Destaca alrededor de 8 a 9 $\mathrm{m}$ del recorrido de la antena la presencia de un límite vertical que nuevamente parece delimitar por el sur el túmulo 3. Además se perciben laderas internas de etapas constructivas previas del túmulo (Figura 28). 


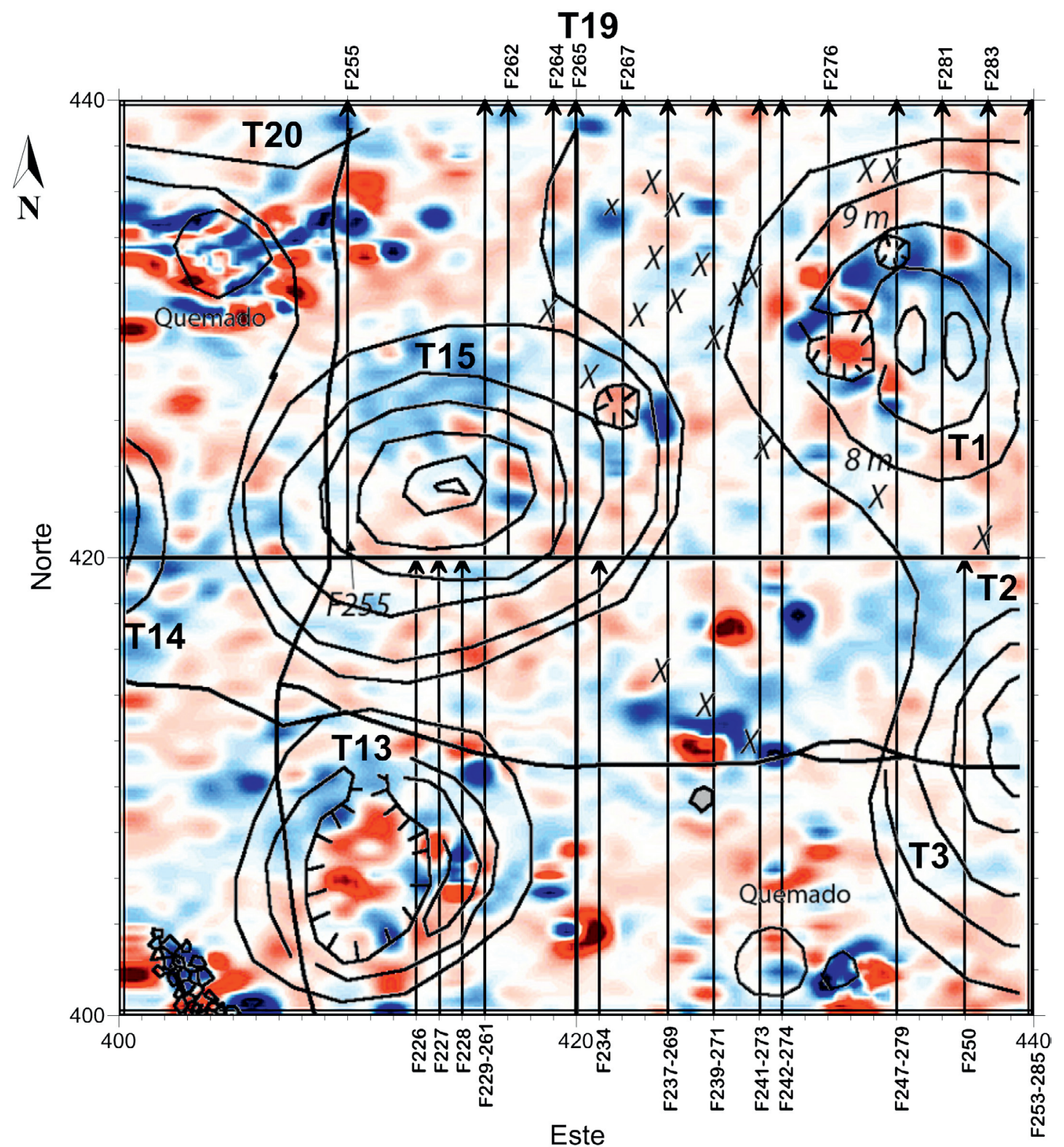

Figura 24. Líneas de georradar trazadas sobre los túmulos y las principales anomalías magnéticas. Position of the georadar lines on the mounds and main magnetic anomalies.

Interpretación de los radargramas de la mitad norte

En este apartado se comentarán las líneas de la mitad norte a excepción de las líneas ya comentadas que se ligaron con las líneas del sur.

En la mitad norte, la línea F255 muestra nuevamente una superficie horizontal en la parte alta del túmulo 15 que parece ser un piso y otra reflexión marcada de 14 a 15 m (Figura 29a). En la línea F262 este piso ya no se observa, pero pueden verse reflexiones notables de 5 a $6 \mathrm{~m}$ y de 16 a 18 m (Figura 29b). En la línea F265 se observa un talud que puede ser reflejo de una etapa previa de acumulación de materiales para formar el túmulo, y entre 12 y $15 \mathrm{~m}$ se ven dos capas superpuestas de acomodo de materiales (Figura 29c). La línea F267 muestra claramente el 

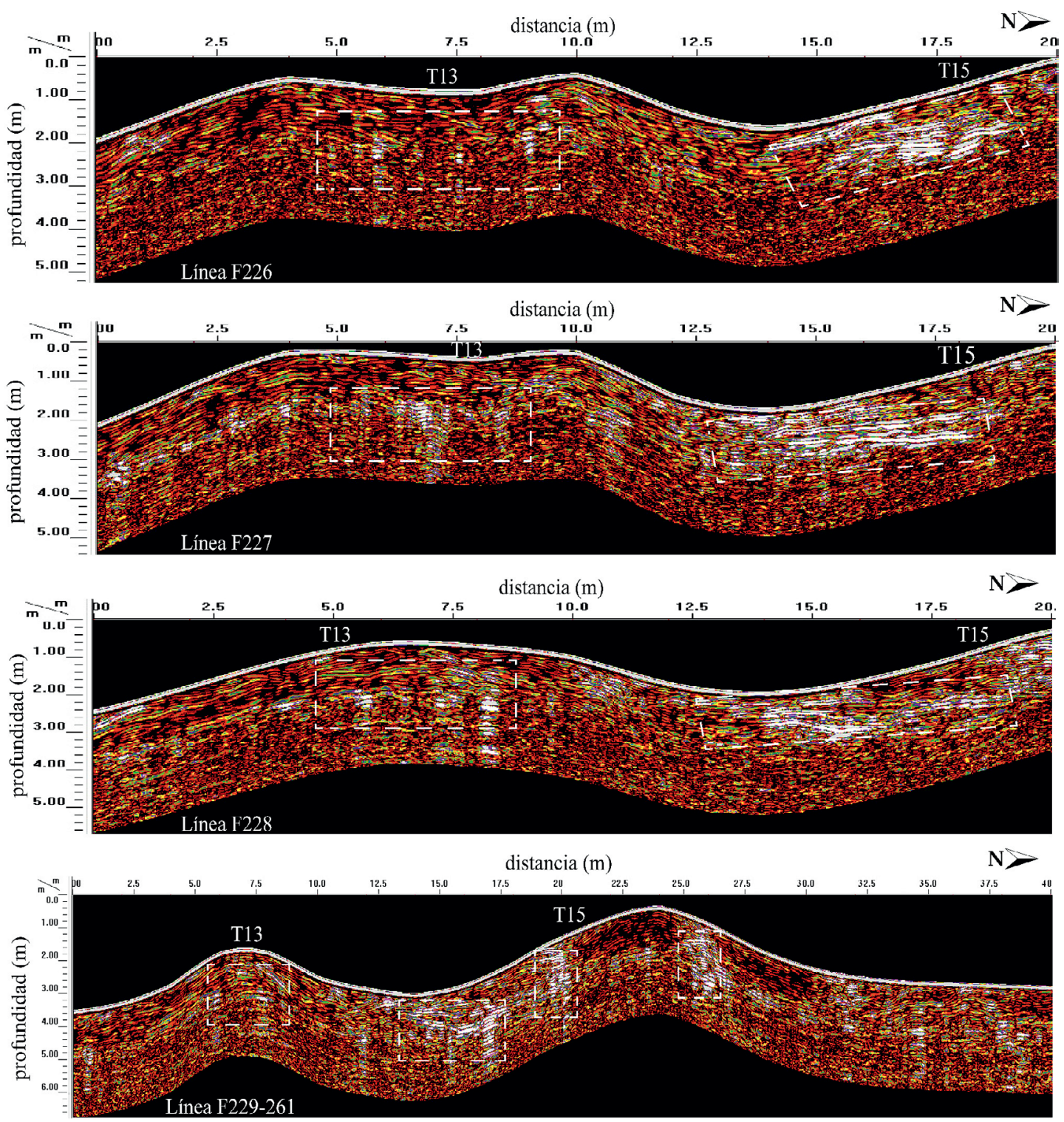

Figura 25. Radargramas (a) de la línea F226, (b) de la línea F227, (c) de la línea F228, (d) de las líneas F229 y F261. Radargrams (a) line F226, (b) line F227, (c) line F228, (d) lines F229 and F261.

perfil de un túmulo más pequeño que puede ser una etapa constructiva anterior. Uno de sus taludes tiene características muy distintas del resto del túmulo (Figura 29d).

La línea F276 corta el túmulo 1 en la parte poniente y muestra el perfil de una etapa anterior. Todo parece indicar que hay dos muros que desde 8 hasta 12,5 m delimitan un elemento central, que aunque alterado en su parte superior, podría contener algo interesante a $2 \mathrm{~m}$ de profundidad en el centro de este espacio. Existen además reflexiones importantes en el final de la línea que se corresponden con las encontradas en la siguiente línea F281 y que también puede ser importante verificarlas con excavación (Figuras $30 \mathrm{a}, \mathrm{b}$ ).

La línea F283 presenta entre 12 y 20 m de distancia una gran cantidad de reflexiones de gran amplitud que se encuentran en la ladera norte del túmulo 1 . Son reflexiones que tienen correspondencia directa con las líneas paralelas anteriores y nuevamente deben ser producto de modificaciones antrópicas (Figura 31). 

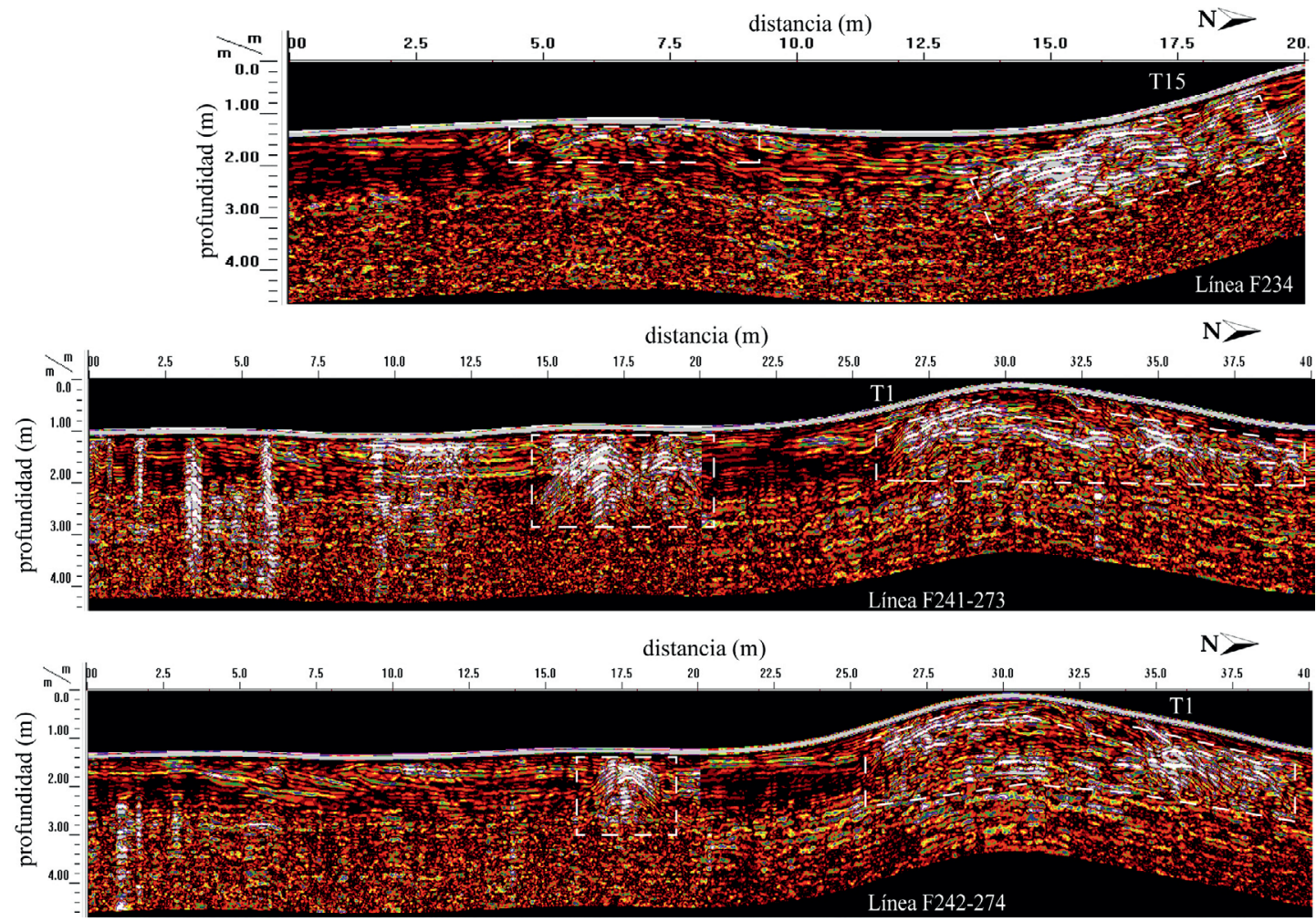

Figura 26. Radargramas (a) de la línea F234, (b) de las líneas F241 y F273, (c) de las líneasF242 y F274. Radargrams (a) line F234, (b) lines F241 and F273, (c) lines F242 and F274.
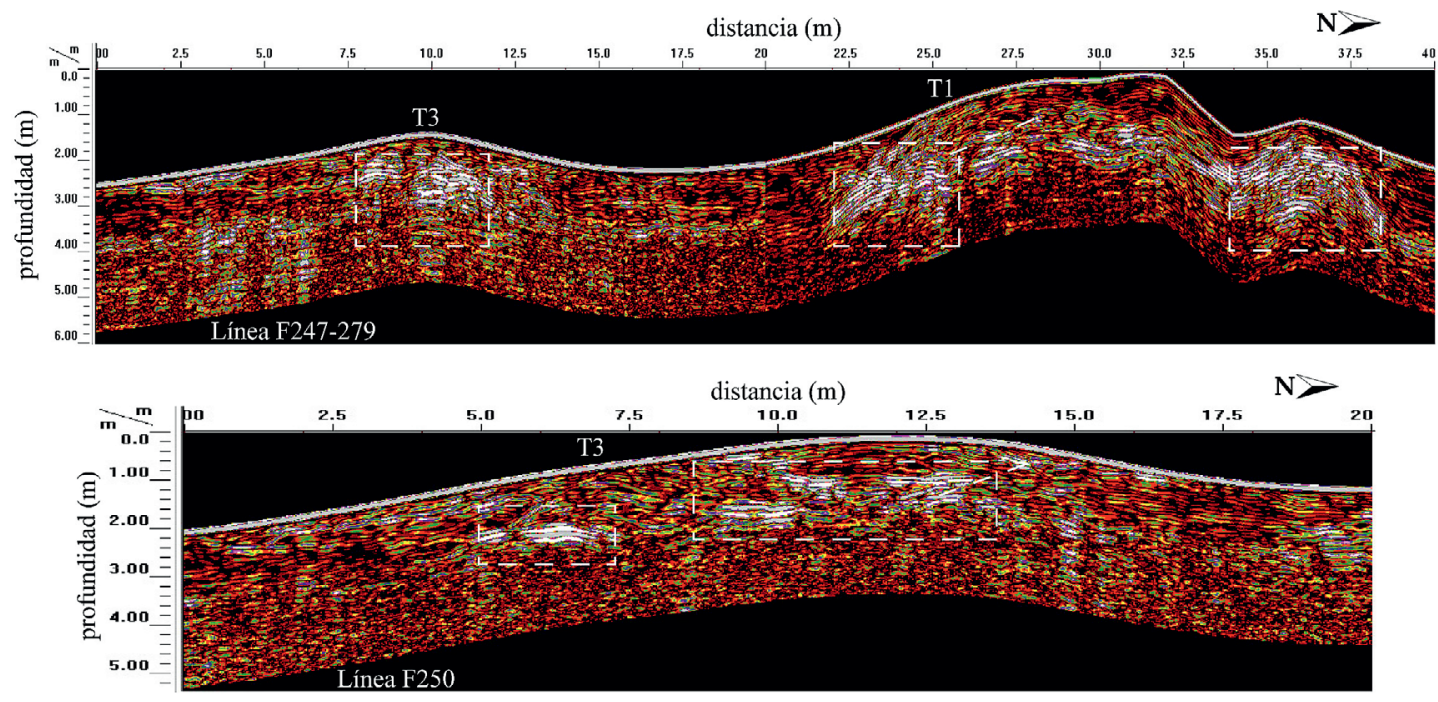

Figura 27. Radargramas (a) de las líneas F247 y F279, (b) de la línea F250.

Radargrams (a) lines F247 and F279, (b) line F250. 


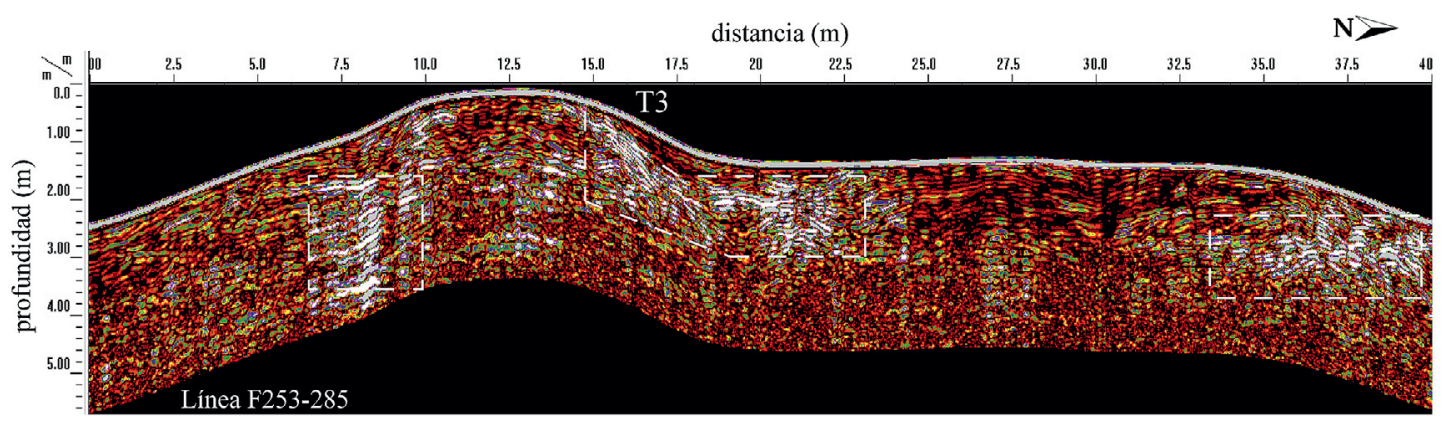

Figura 28. Radargramas de las líneas F253 y F285.

Radargram lines F253 and F285.
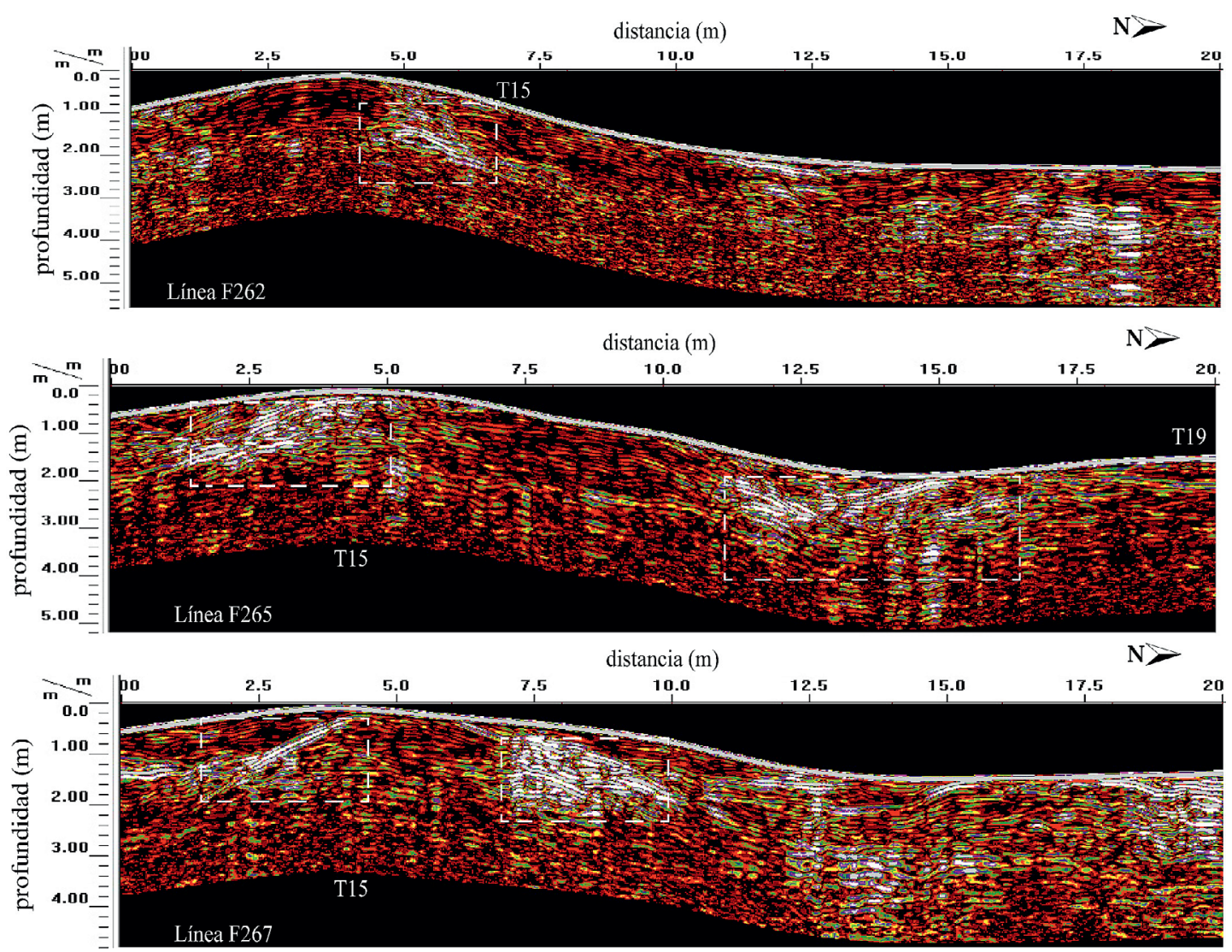

Figura 29. Radargramas (a) de la línea F255, (b) de la línea F262, (c) de la línea F265, (d) de la línea F267. Radargrams (a) line F255, (b) line F262, (c) line F265, (d) line F267.

Por último, todas las líneas quedaron marcadas en la superficie del terreno por el paso de la antena, tienen un metro de separación y muestran el área estudiada con el georradar, también dan una idea del relieve del terreno estudiado en el sitio Az-80 (Figura 31). 

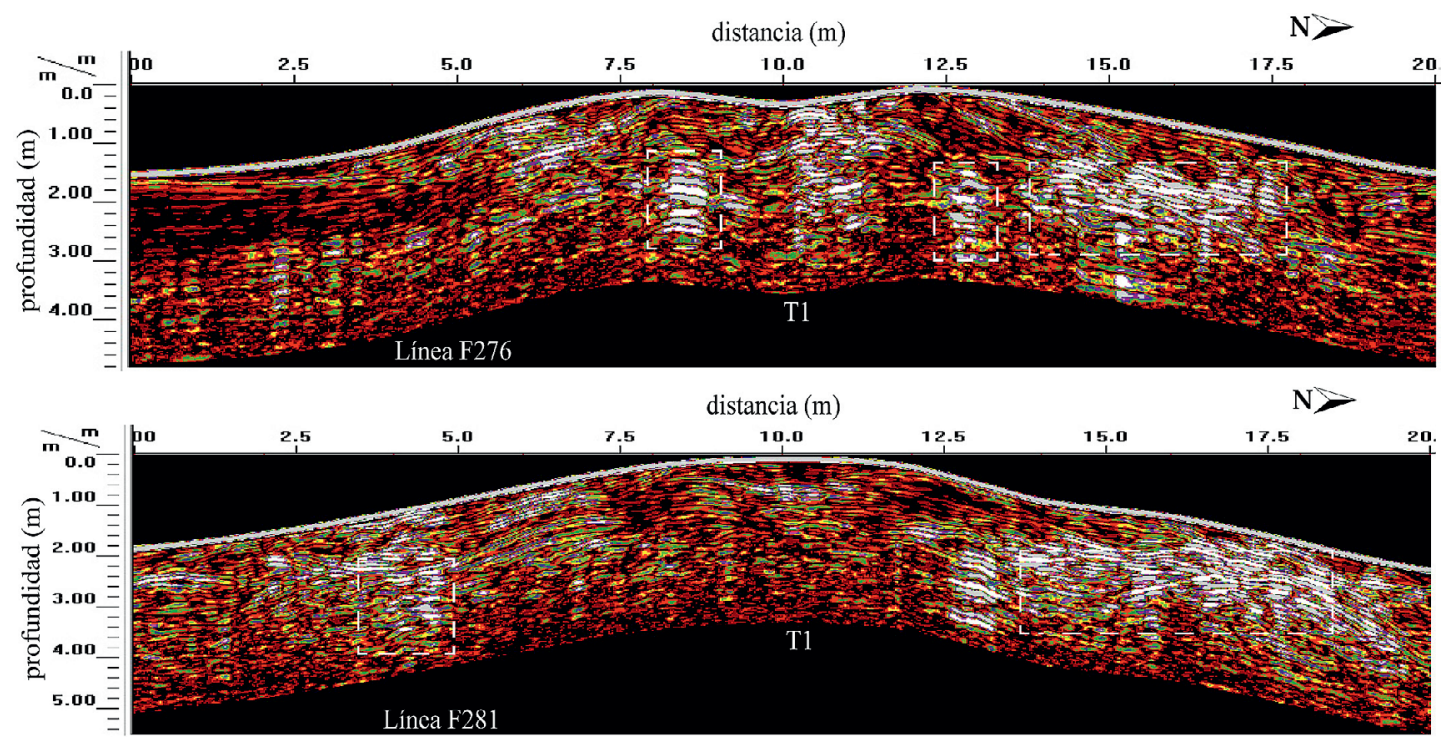

Figura 30. Radargramas (a) de la línea F276, (b) de la línea F281.

Radargrams (a) line F276, (b) line F281.

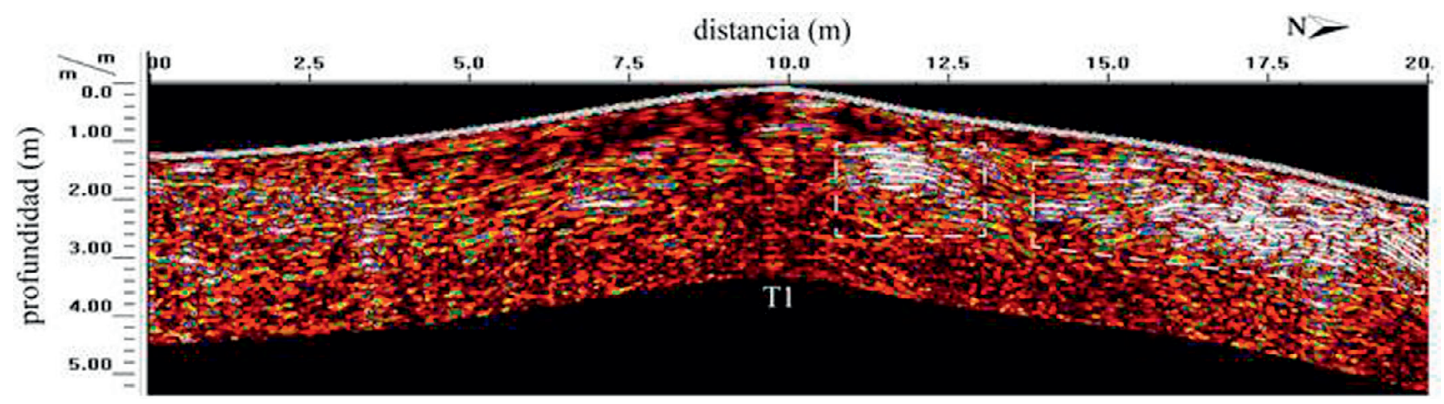

Figura 31. Radargrama de la línea F283.

Radargram line F283.

\section{Consideraciones Finales}

El estudio realizado en los túmulos de los sitios Az-24 y Az-80 del valle de Azapa aprovechó una situación favorable para experimentar con tecnologías de prospección arqueológica en estos contextos de condiciones tan particulares. La ausencia de humedad ha probado ser ideal para la aplicación del georradar y la combinación de esta técnica con el gradiente magnético resulta ser una combinación de técnicas muy adecuada. Como siempre el gradiente ofrece una primera y rápida aproximación a los sitios y en estas condiciones nos mostró la presencia de fragmentos de rocas ignimbríticas traídas de los alrededores. El estudio con georradar ofrece más detalles sobre la forma en que están dispuestos los materiales que forman el túmulo y la profundidad a la que se encuentran.

Ha sido evidente que la distribución de dipolos magnéticos muestra que la presencia de piedras no es aleatoria ni regular. Se concentra en espacios definidos como reflejo de alguna intención de los constructores. Por el momento no podemos conocer cuál fue la intención, pero seguramente las excavaciones que se realicen en el futuro permitirán conocer más acerca de estas prácticas culturales.

La información proporcionada por el georradar es clara y precisa. Ha permitido ver el perfil de lo que parecen ser etapas constructivas previas en el interior de algunos de los túmulos. Esto sugiere que los túmulos mayores son producto de varias etapas de construcción y que posiblemente las superficies 
identificadas en el radargrama estuvieron expuestas y en uso durante algún tiempo antes de ser cubiertas por la etapa posterior. Ha sido muy interesante ver que algunas de estas superficies son horizontales, lo que sugiere la presencia de pisos en algunas de estas etapas previas.

También se han observado materiales acomodados de tal manera que sugieren muros que parecen delimitan espacios importantes en el núcleo de algunos de los túmulos. Esto sugiere la presencia de pequeños recintos rodeados con muros que después fueron recubiertos con las capas alternadas de tierra y material vegetal que forman los túmulos.

En las partes bajas, fuera del perímetro de los túmulos se han detectado reflexiones importantes que también muestran la presencia de materiales enterrados. En varios casos las reflexiones muestran una forma hiperbólica que sugieren la presencia de bultos o cuerpos enterrados a poca profundidad.
Esto desde luego requiere de verificación con una excavación arqueológica controlada.

En resumen, las técnicas utilizadas han mostrado que su aplicación en estos contextos ofrece excelentes resultados, ya que informan sobre las características constructivas de los túmulos identificando etapas previas, posibles intrusiones y enterramientos. Será necesario verificar con la excavación arqueológica las interpretaciones para aumentar la certidumbre en la interpretación de los datos geofísicos que puedan obtenerse en ocasiones futuras.

Agradecimientos: Este estudio es resultado de los proyectos Fondecyt 1130249, UTA 3740-12 y del Convenio de Desempeño UTA-Mineduc. Se agradece al Sr. José Rocha por el material gráfico, topográfico y fotográfico procesado para el presente trabajo. Finalmente se agradecen los comentarios de los evaluadores anónimos de Chungara, que contribuyeron a mejorar este artículo.

\section{Referencias Citadas}

Abbas, M.A., E.A. El-Sayed, F.A. Shaaban y T. Abdel-Hafez 2006. Uncovering the Pyramids Plateau-Giza Plateau in a search for archaeological- relics by utilizing ground penetrating radar. NRIAG Journal of Geophysics, Special Issue, pp. 1-16.

Annan, A.P. y S.W. Cosway 1992. Ground penetrating radar, survey design. Ponencia presentada en el Annual Meeting of SAGEEP, Chicago.

Barba, L., A. Ortiz, J. Blancas y A. Rosales 2008. Georadar studies in a Sand Dune archaeological site in Bahia de Los Muertos, Baja California Sur, Mexico. ISAPNews 16. http://www. archprospection.org/isapnews/isapnews-16. (9 octubre 2014).

Blancas, J. 2000. Principios y Aplicaciones del Método de Radar de Penetración Terrestre (GPR). Tesis de licenciatura en Ingeniería Geofísica, Facultad de Ingeniería, División de Ingeniería en Ciencias de la Tierra, Departamento de Geofísica, Universidad Nacional Autónoma de México, México D.F.

Blancas, J. 2012. Percepción Remota y Técnicas Geofísicas de Prospección para el Estudio de un Asentamiento del Formativo en la Laguna Tlaxcala, México. Tesis de maestría en Ciencias de la Tierra, Instituto de Geofísica, Universidad Nacional Autónoma de México, México D.F.

Bonomo, N., A. Osella y N. Ratto 2013. GPR investigations at an Inca-Spanish site in Argentina. Near Surface Geophysics 11:449-456.

Gaffney, C. y J. Gater 2003. Revealing the Buried Past: Geophysics for Archaeologists, Tempus Publishing Ltd., Stroud.

Geoscan Research 2005. Geoplot Instruction Manual. Main Section. Version 1.97. April 2005. http://www.geoscan-research. co.uk/page22.html (9 octubre 2014)
Hesse, A., L. Barba, K. Link y A. Ortiz 1997. A magnetic and electrical study of archaeological structures at Loma Alta, Michoacan, Mexico. Archaeological Prospection 4:53-67.

Muñoz, I. 1989. El período Formativo en el norte Grande (100 a.C. a 500 d. C.). En Culturas de Chile. Prehistoria, desde sus Orígenes hasta los Albores de la Conquista, editado por J. Hidalgo, V. Schiappacasse, H. Niemeyer, C. Aldunate e I. Solimano, pp. 107-128. Editorial Andrés Bello, Santiago.

Muñoz, I. 2004. Estrategias de Organización Prehispánicas en Azapa: El Impacto de la Agricultura en un Valle del Desierto Costero del Pacífico. Ediciones Universidad de Tarapacá, Arica.

Muñoz, I. 2010. Explotación de los ecosistemas húmedos por los tempranos agricultores prehispánicos del valle de Azapa. Idesia 28:107-115.

Muñoz, I. 2012. Agua y monumentalidad en el valle de Azapa: indicadores del uso del espacio en las poblaciones Alto Ramírez, período Formativo, norte de Chile. Chungara Revista de Antropología Chilena 44:571-592.

Muñoz, I., S. Fernández y J. Rocha 2014. Nuevas dataciones de C14 para los túmulos funerarios: una breve discusión en torno a la cronología de túmulos y la antigüedad del proceso Formativo en Arica. En Mil Años de Historia de los Constructores de Túmulos de los Valles Costeros de Arica. Paisaje, Monumentos y Memoria, editado por I. Muñoz y S. Fernández, en prensa.

Muñoz, I. y M. Gutiérrez 2011. Los túmulos de cerro Moreno: arquitectura en armonía con el paisaje desértico, período agrícola temprano, valle de Azapa, norte de Chile. Anales XXIV de la Reunión Anual de Etnología, pp. 163-78. La Paz. 
Romero, A., C. Santoro, D. Valenzuela, J. Chacama, E. Rosello y L. Piacenza 2004. Túmulos ideología y paisaje de la fase Alto Ramírez del valle de Azapa. Chungara Revista de Antropología Chilena Volumen Especial, Tomo I:261-272.

Santoro, C.M., M.M. Rivadeneira, C. Latorre, F. Rothhammer y V.G. Standen 2012. Rise and decline of Chinchorro sacred landscapes along the hyperarid coast of the Atacama desert. Chungara Revista de Antropología Chilena 44:637-653.

Standen, V.G. y C.M. Santoro 2004. Patrón funerario Arcaico Temprano del sitio Acha-3 y su relación con Chinchorro: cazadores, pescadores y recolectores del desierto de Atacama, costa norte de Chile. Latin American Antiquity 15:89-109.

Transform V3.3. 1990-1996. Data Visualization for 2D Matrix and Image Data. Fortner Research LLC, Inc.

Umire, A. 2013. Rasgos funerarios chinchorro en la costa del extremo sur peruano. Chungara Revista de Antropología Chilena 45:209-235.

Yoshimura, S., S. Tonouchi, T. Nakagawa y W. Daigaku 1987. The Substance of Speech: the First International Symposium on the Application of Modern Technology to Archaeological Explorations at the Giza Necropolis. Waseda University, Tokyo. 